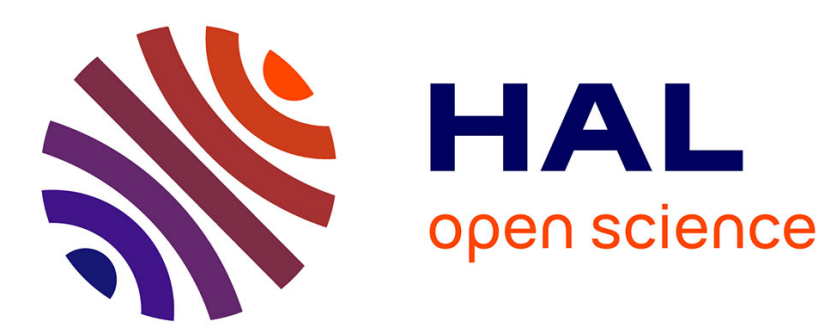

\title{
Mini-Workshop: History of Numerical and Graphical Tables
}

Dominique Tournès, Renate Tobies

\section{To cite this version:}

Dominique Tournès, Renate Tobies. Mini-Workshop: History of Numerical and Graphical Tables. Dominique Tournès and Renate Tobies (eds). Feb 2011, Oberwolfach, Germany. Oberwolfach Reports, 8 (1), pp.639-690, 2011, 10.4171/OWR/2011/12 . hal-01186486

\section{HAL Id: hal-01186486 \\ https://hal.univ-reunion.fr/hal-01186486}

Submitted on 13 Apr 2020

HAL is a multi-disciplinary open access archive for the deposit and dissemination of scientific research documents, whether they are published or not. The documents may come from teaching and research institutions in France or abroad, or from public or private research centers.
L'archive ouverte pluridisciplinaire HAL, est destinée au dépôt et à la diffusion de documents scientifiques de niveau recherche, publiés ou non, émanant des établissements d'enseignement et de recherche français ou étrangers, des laboratoires publics ou privés.

\section{(ㅇ)(1) $\$$}

Distributed under a Creative Commons Attribution - NonCommercial - NoDerivatives| 4.0 


\title{
Mathematisches Forschungsinstitut Oberwolfach
}

Report No. $12 / 2011$

DOI: $10.4171 / \mathrm{OWR} / 2011 / 12$

\section{Mini-Workshop: History of Numerical and Graphical Tables}

\author{
Organised by \\ Renate Tobies, Jena \\ Dominique Tournès, Saint-Denis de la Réunion
}

February 27th - March 5th, 2011

\begin{abstract}
Numerical tables were one of the most commonly used instruments of calculation from the earliest periods for which we have evidence of mathematical activity until the appearance of computing machines. Such tables (including graphical tables) are interesting both as tools of calculation and insofar as traces for certain social and scientific activities of the practitioners by, and for, whom they were produced. Nevertheless, despite the fact that the historical record has preserved thousands of tables from a broad range of civilizations, these tables have themselves received relatively little critical study. Hence, it has seemed to us both useful and innovative to consider the problem of tables in general by bringing together specialists of the different mathematical traditions and of the various professional milieus in which numerical tables have been developed. The workshop allowed us therefore to make significant breakthroughs in our understanding of the places and roles of tables in the history of science, and should bring us to publish a collective book on this subject.
\end{abstract}

Mathematics Subject Classification (2000): 01A16, 01A17, 01A20, 01A25, 01A30, 01A32, 01A35, 01A40, 01A55, 01A60, 11-03, 62-03, 65-03, 65A05, 65S05, 68-03.

\section{Introduction by the Organisers}

The mini-workshop History of numerical and graphical tables was organized by Renate Tobies (Jena) and Dominique Tournès (Saint-Denis de la Réunion). Travel funding was provided by a grant from French National Research Agency (project HTN 2009-2013 "Histoire des tables numériques"). 
The organizers' main goal was to put together a group of 19 participants with a wide range of interests in and around the subject of numerical tables. The meeting was attended by specialists of the different mathematical traditions (Egypt, Mesopotamia, Greece, India, China, the Arabic World, Europe since the Middle Ages) and of the different contexts for the development of tables (astrology, astronomy, metrology, arithmetic, mathematical analysis, numerical calculation, mechanics, physical sciences, engineering, school mathematics, administration and management, etc.).

The schedule began with nineteen talks covering all historical aspects of numerical and graphical tables. Abstracts are proposed in this report in the same order as the corresponding talks were given. For efficiency, these talks were grouped in five sessions on the following themes:

- What is a numerical table, from mathematical and linguistic points of view, and in the modern context of computers?

- Techniques of table calculation (interpolation, finite differences, mechanization).

- Arithmetical tables and other numerical tables.

- Ancient astronomical tables.

- Applications of tables in social and economic life (navigation, artillery, engineering).

The second half of the week was devoted to work more specifically on the project of a future collective book entitled The History of Numerical Tables. A provisional table of contents was elaborated. Some important methodological questions, essential to structure the book and to link chapters between each others, were treated more precisely:

- Texts for tables.

- Interpolation techniques.

- Transmission of knowledge through tables.

- Mechanization of tables.

- Tables in interaction between university and industry.

One consequence of the broad range of backgrounds of the participants is that the meeting was particularly rich and fruitful. A second meeting will take place in France in 2012 to achieve the writing of the book. 


\section{Mini-Workshop: History of Numerical and Graphical Tables Table of Contents}

Dominique Tournès

What is a numerical table? Milestones for a historical research project . 643

Karine Chemla

Texts for tables. A perspective inspired by mathematical manuscripts from early imperial China ........................ 646

Liesbeth De Mol

What is a mathematical table in era of digital computing? . . . . . . . 648

Matthieu Husson

Examples of interpolation in double entry tables in the late medieval

Latin astronomy ...................................... 651

Glen Van Brummelen

Al-Samaw'al and his unusual Sine table: Innovation or academic fraud? 655

Joachim Fischer (joint with Bärbel Ruess)

Napier revisited or A further look at the computation of his logarithms . 656

Marie-José Durand-Richard

For what kind of tables Charles Babbage's "Difference Engine" and

"Analytical Engine" were conceived? ........................ 658

Micah T. Ross

Survey of graphical and numerical tables in Egypt .............. 660

Christine Proust

On the nature of the table Plimpton 322 ................... 662

Agathe Keller

Composing material for the HTN book after the IMERA International

Workshop on Numerical Tables in Sanskrit .................. 665

Maarten Bullynck

Projects and networks of tables in number theory: A proposal for

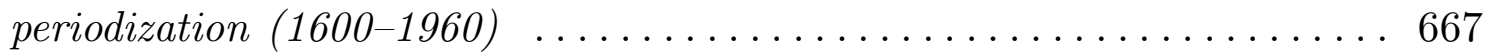

Mathieu Ossendrijver

Tabular texts of Babylonian mathematical astronomy ............. 670

Nathan Sidoli

Mathematical tables in Ptolemy's Almagest ................... 672

Clemency Montelle

Astronomical tables in second millennium Sanskrit sources .......... 675 
Mahesh Koolakkodlu

Vākyas: Astronomical tables in sentences .................6677

Thomas Sonar

On the development of navigation tables in early modern England . . .. 679

David Aubin

Range tables at the beginning of the twentieth century ............. 682

Renate Tobies

Numerical and graphical tables developed in interaction between university and industry in the first half of the 20th century ................ 684

Denis Bayart

Numerical sampling tables in industry: Design and practice ........ 686 


\section{Abstracts}

\section{What is a numerical table? Milestones for a historical research project DOMINIQUe TOURnès}

What is a numerical table and why does this object interest historians of mathematics? Since the beginning of the HTN project, we have listened to more than fifty talks on this subject, sometimes contradictory. From these various points of view, we must decide what is finally a numerical table. What is therefore the exact field of our project? What definition to adopt to delimit this field with precision?

For me, a "numerical table" - at least in its most elementary form - could be defined as a list of lists of numbers having same length $n(n \geq 2)$, when this list is used to express a correspondence between $n$ sets of numbers (by "numbers", I understand here either abstract numbers, or concrete measurements). The "mathematical dimension" of such a table is $n-1$, the number of independent variables in the relation represented by the table.

It is important to distinguish this formal notion of numerical table from the question of the material presentation of a set of data, numerical or not, in a tabular form with lines, columns, or other graphic codes invented to organize the data spatially and to make appear some of their properties. The word "array" could be used here to refer to this second point of view. As an example, I could mention the numerous arrays of numbers found in Leibniz's papers. These arrays were used as a heuristic tool to explore relations between series of numbers and to discover new theoretical results, but they are not numerical tables in our sense. The situation is the same when we place numbers in a particular spatial disposition on a sheet of paper or on an abacus to execute an arithmetical operation on these numbers. We put numbers in a tabular form to facilitate the application of an algorithm, but we cannot speak here of a numerical table.

A table can adopt a purely textual shape. It can also be written simply as a list of lists of numbers, in a linear presentation, inserted or not into an explicative text. These two first forms seem to be frequent in ancient texts, related to small sets of data. Beyond these primitive forms, we encounter three fundamental types of numerical tables ([1], 91):

1) tables of dimension one, associated with functions of one independent variable, commonly presented as two lists face-to-face (e.g. table of squares, table of cubes, logarithmic table, trigonometric table, etc.);

2) tables of dimension two, associated with functions of two independent variables, commonly presented as a double entry array (e.g. multiplication table, table of binomial coefficients, Legendre's tables of elliptic integrals of the first and second kinds, etc.);

3) tables of dimension three, associated with functions of three independent variables, that can be presented as a three-dimensional array, or, in other terms, a collection of two-dimensional arrays, one for each value of the third variable; this 
last kind of table presents itself as a book, and is concretely impossible to realize if the values to be tabulated are somewhat numerous.

This physical limitation of the dimension of tables that can be displayed on paper is one of the reasons why nineteenth century engineers oriented themselves towards graphical tables (called "nomograms") to represent relations between more than three variables. Of course, a graphical table is a particular form of numerical table, in the sense that when one uses a graphical table, the data and the results are numbers. Between the two, there is a translation process, in the direct sense from numbers to geometrical quantities, and in the inverse sense from geometrical quantities to numbers.

All that we have seen before shows that the notion of numerical table is linked intimately to the concept of function. In a famous paper published in 1976 [2], Youschkevitch already suggested this link, without going perhaps far enough in this direction. During a long time, outside of a merely verbal description, the numerical tables constituted perhaps the only way to express precisely a dependence relation between two or more than two quantities. From 16th to 19th century, analytical expressions took precedence to such an extent that the notion of function merged itself with the one of analytical formula, either finite or infinite, permitting the calculation of a value from other values on which it depends. However, the necessity of transforming these analytical formulas into numerical tables for applications remained a major preoccupation for astronomers, physicists, and engineers. In particular, tables were necessary to numerically integrate differential equations without solutions in finite form. Throughout this period, around one thousand tables of special functions have been computed to answer the needs of practitioners.

The most recent definitions of a function, elaborated from the end of the 19th century with the beginnings of set theory, again appear to be curiously close to the notion of table. To modern sensibilities, a relation between elements of two sets of numbers $\mathrm{X}$ and $\mathrm{Y}$ is a set of ordered pairs $(x, y)$, where $x \in X$ and $y \in Y$. A function is simply a particular case of relation, when every element of $\mathrm{X}$ is associated at most to one element of Y. We recover, more or less, our initial definition of a one-dimensional numerical table: a list of ordered pairs of numbers. The only difference is that a relation is a complete virtual table, with all possible values, the number of which can be infinite, while a numerical table is only, in general, a sample of a theoretical relation, with missing values to be interpolated. The conclusion is therefore that a true "tabular concept of function" is effectively present during all history of mathematical analysis.

Some attempts have been done to inventory and classify numerical tables. I could mention the 1873 impressive report by Glaisher [3] for the British Association for the Advancement of Science, though this report considered only mathematical tables in the strict sense. Another important work was made in USA in 1940 by a Committee created by the National Research Council. A new classification took into account the numerical tables used in a lot of human activities outside mathematics: interest and investment, actuarial science, engineering, astronomy, 
geodesy, physics, chemistry, navigation. As a consequence, a specific journal entitled Mathematical Tables and Other Aids to Computation was published from 1943, denoting the importance of this subject for scientific and economic life.

Outside these old surveys, the secondary sources on the subject are poor. We can quote only one recent monograph on tables: The History of Mathematical Tables. From Sumer to Spreadsheets [4]. In spite of its great interest, this book is incomplete: several ages, several civilizations, several types of tables are missing in its contents. So, for instance, there is nothing on Ptolemy's chord tables, nothing on trigonometrical and astronomical Arabic and Indian tables, nothing on Latin medieval tables, almost nothing on the hundred of tables of special functions calculated in the 19th century. In addition, if certain categories of professional tables are well represented in the book, such as tables for banks and insurances and certain astronomical tables, others, like ballistic tables or tide tables, are completely overlooked. Lastly, the reader might especially regret that ten chapters out of twelve are devoted to Great Britain and the United States. One would have wished a much more significant consideration for continental Europe, in particular France, Germany and Russia.

The HTN project is born precisely in 2003, after the publication of this book. It appeared immediately that it would be necessary to write a second volume on the subject of numerical tables. In complement to the topics enumerated before, it would be important to deepen several important methodological questions, for example:

1) Tables as a significant element in the analysis of circulation of knowledge between periods, between countries and between professional communities.

2) Role of numerical tables, of their presentation in multidimensional arrays, and of interpolation techniques in the emergence and development of the modern concept of function.

3) Uses and roles of tables in scientific activity: ways of presenting methodically a set of data or the results of a research, instruments for making calculations easier, heuristic tools for exploring new situations, etc.

4) Interactions between numerical tables, graphical tables, and mechanical instruments conceived to calculate or construct them.

\section{REFERENCES}

[1] J. d'Alembert et al., Article Tables in: Encyclopédie méthodique. Mathématiques, Paris: Panckoucke, 1789, 91-94.

[2] A. P. Youschkevitch, The concept of function up to the middle of the 19th century, Archive for History of Exact Sciences 16(1) (1976), 37-85.

[3] J. W. L. Glaisher, Report of the Committee, consisting of Professor Cayley, F.R.S., Professor Stokes, F.R.S. Professor Sir W. Thomson, F.R.S., Professor H. J. S. Smith, F.R.S., and J.W. L. Glaisher, B.A., F.R.A.S. (Reporter), on Mathematical Tables. In: Report of the Forty-Third Meeting of the B.A.A.S. Held at Bradford in September 1873, London: John Murray, 1874, 1-175.

[4] M. Campbell-Kelly, M. Croarken, R. Flood, and E. Robson (eds.), The History of Mathematical Tables. From Sumer to Spreadsheets, Oxford: University Press, 2003. 


\section{Texts for tables. A perspective inspired by mathematical manuscripts from early imperial China}

\section{KARINe CHEMla}

This talk was devoted to numerical tables found in mathematical manuscripts excavated in the last decades in China and dating to the third and the second century before the Common Era. In this respect, it presented the first of three parts that will constitute the chapter on China that I prepare for the book. As I have shown elsewhere, the constitution of Chinese mathematical sources underwent a key shift in about the tenth century $([1],[2])$. By contrast to sources written until roughly speaking the eighth century, in which we find only discourse, extant mathematical documents from the tenth century onwards abound in non-discursive elements. This shift can be perceived in the text of tables. Whereas tables have to be identified in texts of the first time period as parts of discursive texts, later sources include tables realized from a textual viewpoint as arrays of numbers or diagrams. The third part will allude to the shift that occurred in the seventeenth century when numerous numerical tables were translated on the basis of Western sources.

In addition to describing tables found in the excavated manuscripts and which represent the tables inserted in texts of the first time period, the talk aimed at suggesting elements of reflections on the text of tables more generally. The first table discussed was taken from the Book of mathematical procedures, found in a tomb sealed in $c a .186 \mathrm{BCE}$ [5]. The manuscript is written on bamboo strips that were once tied to each other. Its clauses each have three entries: two quantities expressed with numbers written in characters and explicit measuring units for length, being multiplied, yield a third quantity, expressed with the same kind of numbers and with respect to the same measuring units, which now express the extension of a surface. The text is made of clauses verbally complete. It organizes the clauses in sets sharing the first same entry, which is not repeated. It is not clear whether the set of clauses is complete. However, one can perceive an arrangement of the clauses in a set. The second text in the same book, which deals with multiplications by each other of powers of 10 or of a power of 10 with $\frac{1}{2}$, has only complete clauses. Its entries are abstract numbers, still written, as are all the tables from this first time period, in Chinese characters. On the other hand, no principle can be easily detected as to the organization of the set of clauses. This raises the question of the function of such a table.

Likewise, the book Mathematical procedures found in a tomb sealed before $157 \mathrm{BCE}$ and also written on bamboo strips once tied to each other, has a table for multiplying powers of 10 [4]. Its text is organized in registers, from top to bottom, and they must clearly be read one register after the other. The set of clauses is complete, and its organization is clear: In a first set of clauses, the first entry does not change while the second entry describes a list of increasing powers of 10 . Then the first entry shifts to the next higher power of 10 , and the second entry describes a list of increasing powers of 10, starting from the same as the first member, and so on. So the first entry describes the list of powers of 10 with a larger step than the second entry. One can perceive its link to texts in 
which the first unchanging entry is put once and for all at the beginning of a set of clauses. Despite some irregularities, the table is organized in such a way that one can retrieve a clause if needed. These remarks bring to light that on the same topic - multiplying powers of 10 -, one could write down tables in a completely different way. The table of multiplication from the Qin dynasty found in a well at Liye and written this time on a wooden board contains a table of multiplication that is organized according to similar principles. The clauses are not completely verbalized, containing basically the sets of entries. Each clause is placed in a column of a registers and registers are read from right to left and then from top to bottom. The first entry describes a decreasing sequence of digit from 9 to 2 , while the second remains constantly equal to 9 . Once the first entry has reached 2 , the second entry of the next clause is transformed into 8 and the first entry starts describing the same list between 8 and 2, avoiding any repetition of clauses on the basis of a principle of symmetry and so on. One can perceive that the organization of clauses in this table is quite similar, even if it is reverse to, that of the table described previously. This comparison brings to light a recurring pattern for organizing clauses in a table, probably in relation to a kind of use (pick-up clause) of the table. One may also assume that such tables were memorized.

If we want to focus of the kind of text shaped to write down a table in such writings, the key point is to note that the end of a clause in the last two tables is indicated by an empty character followed by a space that the reader translates into going to the next column (and not to the following item on the same bamboo strip) to find the next clause. However, similar kinds of table can be found in manuscripts where the texts with which they are written are of another kind: they are materialized in a running text that uses another kind of indicators to mark the separation of clauses. In addition to the same empty character, often placed at the end of a clause, a sign of punctuation, which is regularly used to separate items in a text that could be wrongly associated, is almost systematically used in manuscripts to separate clauses of tables written continuously. The manuscripts thus show the shaping of two kinds of text to write down tables, in some cases similar tables are found in either one or the other format.

Once one has thus identified the markers of such texts of tables, one notices that there are several passages in the Book of mathematical procedures that are tables. We have tables for equivalences between measuring units (for which the manuscripts contain a text of table in either one or the other format); tables of data; tables of procedures; tables of results of problems and mixture of these elements. Most of the last kinds of table relate to grains, which appear to have been a topic easily lending itself to the use of tables. A striking result of the identification of this set of tables is that it appears that the first chapter of the book handed down through the written tradition, Mathematical Canon of Master Sun (ca. 400) [6], is essentially composed of tables.

Other, later, manuscripts which were found in the cache sealed in Central Asia, in Dunhuang, in about the year 1000, also contain tables. A table of multiplication is realized on paper, textually in exactly the same way as was the wooden board 
found at Liye. A key innovation is that it contains not only numbers written in characters, but the results of the multiplication are also written with the representation of how numbers were written on the counting surface with counting rods. A second table, the dimensions of which are much larger than anything known before, presents the results of products of length and width of fields written with respect to measuring units specific to surface and not decimal. This table presents a second key innovation, which is its tabular layout. It is a double-entry table. With these two innovations, we have entered a wholly new world of mathematical documents. They are written on paper and they contain more elements than simply characters. The second part of the chapter will be devoted to them.

Some tables, found in Chinese sources and coming through translations of Sanskrit material will be dealt with in the chapter dealing with transmission. Perhaps the same option will be taken for tables influenced by Arabic or by Latin sources.

\section{REFERENCES}

[1] K. Chemla, Variété des modes d'utilisation des tu dans les textes mathématiques des Song et des Yuan, From Image to Action: The Function of Tu-Representations in East Asian Intellectual Culture, 2001.

[2] K. Chemla, Changes and continuities in the use of diagrams tu in Chinese mathematical writings (3rd century-14th century) [I], East Asian Science, Technology, and Society. An International Journal 4 (2010), 303-326.

[3] K. Chemla and MA Biao, Interpreting a newly discovered mathematical document written at the beginning of Han dynasty in China (before 157 B.C.E.) and excavated from tomb Mr7y at Shuihudi, Sciamvs, accepted.

[4] Hubei sheng wenwu kaogu yanjiusuo and Yunmeng xian bowuguan, Hubei Yunmeng Shuihudi M77 fajue jianbao, Jiang Han kaogu 10 (2008), 31-37 + Plates 11-16.

[5] Peng Hao, Zhangjiashan hanjian "Suanshushu" zhushi (Commentary on the Book of mathematical procedures, a writing on bamboo strips dating from the Han and discovered at Zhangjiashan), Beijing: Science Press (Kexue chubanshe), 2001.

[6] Qian Baocong, Suanjing shishu (Qian Baocong jiaodian) (Critical punctuated edition of The Ten Classics of Mathematics), 2 vols., Beijing: Zhonghua shuju, 1963.

\section{What is a mathematical table in era of digital computing?}

\section{Liesbeth De Mol}

Is it true that the development of the digital and programmable computer resulted in the end of the numerical table? It is clear that those involved with table making and/or digital computing during the pioneering years of the modern computer, were quite pessimistic about the future of projects such as the Mathematical Tables Project and the need for mathematical tables in general. Indeed, as Ida Rhodes, one of the participants of the MathTable project and computer pioneer, recounts:

When the ENIAC ${ }^{1}$ was finished, [Dr. Lowan] was invited to watch it. [He] came back and said, "We're finished. They don't need us anymore. Do you know [what] they do? They don't look up Tables. They actually compute each

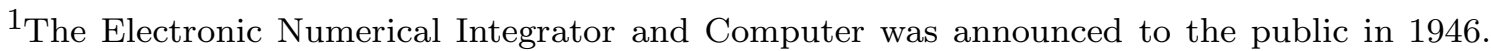
It was the first electronic computer that was basically general-purpose (it could be externally programmed).
} 
value ab ovo." And to me that sounded so impossible, so incredible. [Not] to have to look up one of our marvelous Tables. That sounded like [the] death knell.

This pessimism about the future of mathematical tables, given the computer, seems to be echoed in the relatively recent volume The History of Mathematical Tables. From Sumer to Spreadsheets [2]. It is suggested that only one spark of hope is left for the future of mathematical tables, i.e., the table-as-spreadsheet. But is this really all there is to say about mathematical tables in the digital era? It is argued here that the role of mathematical tables extends well beyond that of the table-as-spreadsheet provided that one accepts that certain aspects of numerical tables have changed significantly. As a consequence, the numerical table as it was used, represented and computed before the rise of the electronic computer, has evolved considerably. But what exactly has changed? What exactly is meant with mathematical table in the digital era? Does one need an unreasonable generalization of the notion of a mathematical table so as to include tables in the digital era, with the consequence of undermining the very notion? In order to tackle these kind of questions the history of the electronic computer must be taken into account. Two significant evolutions in this context are (1) the development of faster computers with ever increasing digital memory and fast memory access techniques (programming and hardware) and (2) further internalization of certain computational processes into the machine.

The current research is mainly based on a study of papers from computer science and engineering journals (mainly Communications of the ACM) as well as the journal Mathematical Tables and Other Aids to Computation and its successor Mathematics of Computation. Despite the fact that this results in a focused and specialized corpus, the findings from this study open up the scope of the mathematical table. The different cases studied at least challenge the traditional notion of a mathematical table as a $2 \mathrm{D}$ text printed on paper.

One new and major category of mathematical tables are what one could call digital tables, i.e., tables that are internalized into the computer and that are not there for humans but for computers. It is shown in my talk that up to today such digital tables play an important role in digital computing, going from the use of look-up tables in digital image processing, the use of symbol and hashing tables in compilers or the efficient organization of data (hash tables). A borderline and instructive example of such tables are the ENIAC function tables. These were physical objects built as numerical tables [4]:

$[T]$ hey can be used to store values of one or more functions tabulated against an independent variable and can be programmed to look up and transmit the values so stored.

These tables were used initially for interpolation for making firing tables but were later used to turn ENIAC into a stored program computer. The ENIAC had three function tables, each able to store up to 104 entries, an entry consisting of at most 12 digits and a sign. A fundamental feature of these tables is that, in contrast to the "classical" printed 2D table, the "user" of these tables is not a human but a machine. Because of this, these tables are wired into the computation. Evidently, 
this changes the idea of a mathematical table. Since the table is being wired into the computational process, it is not only able to store but also to transmit a value. The tables also contain certain programming facilities. Each program control of the function table offers for instance the operation option as to wether a tabulated entry or its complement is to be looked up and transmitted. For every new computation the function tables could be reset and switched anew to store different values, depending on the mathematical tables one needed. As such, these function tables are merely carriers of mathematical tables. However, it is also because of this possibility of resetting and switching the function tables that these tables can be used not only for different purposes (read: computations) but also in different ways. One could not only use them to store 104 values of three different functions, but, using special adaptors (shifter-deleter adaptors) on the so-called "numerical" cables (carrying digital pulses as numbers) one could for instance "wire" them to store 104 times 12 digits (see [1] or [3] for an example of such usage). It was exactly this kind of usage that ultimately resulted in the use of the function tables as part of the rewired ENIAC as a stored program computer. Once wired in this way, it was no longer necessary to externally wire a program on ENIAC. Programs could now be fed into the machine by means of the punched cards. The function tables were now permanently switched and used by ENIAC as a means to execute orders. Hence, they were turned into permanent tables and became an essential part of the interpretation of the algorithms to be executed. In this way, mathematical tables slowly evolved from tables that store numerical values as numerical values to be used in a computation to tables that store numerical values as symbols that code instructions, the table thus becoming (part of) an algorithm rather than being used by one.

The fact that a mathematical table is used internally within the computer however not only affects our notion of table but also affects the way tables are used and computed with. First of all, one needs to include into the algorithm which uses the table (for instance an interpolation algorithm) also the way it should access the table, when it should access the table, etc. Secondly, and this becomes more and more important the larger the digital tables being used, one needs to think about the efficient organization of data into the tables and good algorithms to find a given piece of datum. In this context the use of the hash table format for symbol tables in compilers offers an interesting example.

Of course, the electronic computer not only opened the way for digital tables. It has been and is used to compute (values from) mathematical tables. Also this affects the thinking of the human "table-maker". First of all, the fact that one uses a computer to compute tables changes the algorithms that underly these computations. This was understood from the very beginnings of the digital and programmable computer. For instance, a "computer-adapted" algorithm was used in a number-theoretical computation that was set-up on ENIAC and which was used to extend and debug existing tables of exponents of $2 \bmod p$ (see [1], [3]). Secondly, if one is dealing with "explorative" tables (see Bullynck's abstract in this volume) the computer can also be used to explore the tables and this again affects 
the algorithms one devises. Furthermore, since the tables are no longer explored by humans they will be organized in a different manner and, once "explored" might be thrown away. Finally, the computer has also made it possible to directly compute values of a given mathematical table in a reasonable amount of time, a fact that explains the pessimism of table-makers about the future of tables in the digital era. In these cases, attention has shifted from the efficient making and organization of tables to the development of efficient algorithms to compute such values. However, several examples show that it is only partially true that printed mathematical tables have been replaced by computer programs that generate them. Whether one choses a table or an algorithm largely depends on the usage one has in mind, the speed of the available algorithms and hardware, the size of the memory and the computational effort needed to retrieve information from it.

Confronting these findings with the pessimistic attitude toward the future of mathematical tables, it is important to make a careful distinction between tables for external, human usage and tables for internal computer use (viz. digital tables). Taking into account this distinction, it is clear that mathematical tables in the digital era indeed challenge our notion of table, raising a lot of fundamental questions. Instead of being the end of the mathematical table, the electronic computer opens up a promising future for this old mathematical tool, making it a relevant tool for humans and computers, provided one accepts the challenge.

\section{REFERENCES}

[1] M. Bullynck and L. De Mol, Setting-up early computer programs: D. H. Lehmer's ENIAC computation, Archive for Mathematical Logic 49(2) (2010), 123-146.

[2] M. Campbell-Kelly, M. Croarken, R. Flood, and E. Robson (eds.), The History of Mathematical Tables. From Sumer to Spreadsheets, Oxford: University Press, 2003.

[3] L. De Mol and M. Bullynck, A week-end off: The First Extensive Number-Theoretical computation on the ENIAC, in: A. Beckmann, C. Dimitracopoulos, and B. Löwe, CIE2008, LNCS, 5028, 158-167, 2008.

[4] A. K. Goldstine, Report on the ENIAC, technical report I, Technical report, Moore School of Electrical Engineering, University of Pennsylvania, Philadelphia, June 1946.

\section{Examples of interpolation in double entry tables in the late medieval Latin astronomy \\ Matthieu Husson}

The topic of interpolation could usefully result in either an independent chapter of the book or in cases studies which enrich other chapters depending on the adopted organization of the book. Specifically, two examples of interpolation in the double entry tables of 14th century Latin astronomy exemplify broader issues of interest for many of us.

John of Muris Tabule permanentes. The Tabule permanentes are double entry tables conceived of and computed by John of Muris and laid out by Firmin of Beauval between 1320 and 1330. They are designed to compute the time of 
true conjunction of the sun and the moon from their mean argument, an important step toward the computation of eclipse. Tables and canons have been edited separately by modern scholarship (tables in [1], canons in [2]). The editors of the tables relied on 11 manuscript copies of the work mainly from 15th century Vienna around Peueurbach, Gmunden and Regiomontanus ${ }^{1}$. All of the Vienna manuscripts contain only works of mathematical astronomy. In fact there is only one copy transmitted to us in an astrologically oriented environment ${ }^{2}$. All these little codicological particulars will be of importance in the summary of the presentation.

Muris proposed two distinct interpolation procedures. We will, for the sake of brevity, present them in modern algebraic notation. The reader needs to know that although we get a compacted presentation this way, we lose the rhetorical feel of the presentation of algorithm and we completely eliminate important mathematical issues concerning the uses of signs in complex computation. Let us represent the table with the following array in which the capital letters stand for the value present in the table and the small one to values absent of the table:

\begin{tabular}{|c|c|c|c|c|}
\hline & & $\mathrm{L}_{1}$ & $l$ & $\mathrm{~L}_{2}$ \\
\hline & & & & \\
\hline $\mathrm{S}_{1}$ & & $\mathrm{D}_{1}$ & & $\mathrm{D}_{2}$ \\
\hline$s$ & & & $d$ & \\
\hline $\mathrm{S}_{2}$ & & $\mathrm{D}_{3}$ & & $\mathrm{D}_{4}$ \\
\hline
\end{tabular}

More precisely the ' $S$ ' and ' $s$ ' stand for the sun mean argument, the ' $L$ ' and ' $l$ ' the moon mean argument and the ' $D$ ' and ' $d$ ' for the difference between the time of conjunction to the time of true conjunction. We enter the table with $s$ and $l$ so we need to interpolate $d$. In the general case we are asked to use the following procedure:

$$
d=\mathrm{D}_{1}+\frac{l-\mathrm{L}_{1}}{\mathrm{~L}_{2}-\mathrm{L}_{1}} \times\left(\mathrm{D}_{2}-\mathrm{D}_{1}\right)+\frac{s-\mathrm{S}_{1}}{\mathrm{~S}_{2}-\mathrm{S}_{1}} \times\left(\mathrm{D}_{3}-\mathrm{D}_{1}\right) .
$$

And in the near zero case we should use this other more complex and somehow recursive procedure:

$$
\begin{aligned}
n_{1} & =\mathrm{D}_{1}-\frac{l-\mathrm{L}_{1}}{\mathrm{~L}_{2}-\mathrm{L}_{1}} \times\left(\mathrm{D}_{2}-\mathrm{D}_{1}\right) \\
n_{2} & =\mathrm{D}_{3}-\frac{l-\mathrm{L}_{1}}{\mathrm{~L}_{2}-\mathrm{L}_{1}} \times\left(\mathrm{D}_{4}-\mathrm{D}_{3}\right) \\
n_{3} & =n_{1}-\frac{s-\mathrm{S}_{1}}{\mathrm{~S}_{2}-\mathrm{S}_{1}} \times\left(n_{2}-n_{1}\right) \\
\text { If } n_{3} \geq n_{1} \text { then } d & =n_{1}+n_{3} \text { and if } n_{3} \leq n_{1} \text { then } d=n_{1}-n_{3} .
\end{aligned}
$$

\footnotetext{
${ }^{1}$ One of the copies is from Gmunden's hand (Vienna, Nationalbibliothek, MS. 5268) and another one (Nürnberg, MS. Cent VI 23) seems to have been the property of Regiomontanus.

${ }^{2}$ Metz, Bibliothèque municipale, MS. 287 seems to come from the Metz cathedral and to have been composed in the 15 th century.
} 
Three remarks are in order at this point:

(1) We have presented the algorithm as a sequence of formulas in order to reflect the rhetoric presentation made by the canon.

(2) This last procedure can be understood as the consequence of a desire to take a closer account of the moon movement near the zero position.

(3) The variation in the interpolation procedure results from the mathematical situation (near zero of the tabulated function) and the nature of the change is best explained by an astronomical consideration.

John of Lignieris Tabule magne. The Tabule magne are also double entry tables realized by Ligneris in the same period than the Tabule permanentes. They are designed to compute the equation of each planet directly from the mean argument and mean center of the planet. Three manuscript copies are known ${ }^{3}$. Two of them are in Paris and were produced in the 15th century by a humanist publisher context. Both are of theoretical and mathematical content but in a rather different way than those of the Tabule permanentes coming from Vienna: there are no tables at all in the Lat. 7281 which is best understood as a first "history" of medieval astronomy. The Erfurt manuscript contains technical material and is closely connected to John of Saxony a pupil of Ligneris producer of one of the most popular canons of the Alphonsine tables. Using the same kind of convention as before we can summarize the interpolation algorithm found in these manuscripts in the following way:

\begin{tabular}{|c|c|c|c|c|}
\hline & & $\mathrm{C}_{1}$ & $c$ & $\mathrm{C}_{2}$ \\
\hline & & & & \\
\hline $\mathrm{A}_{1}$ & & $\mathrm{E}_{1}$ & & $\mathrm{E}_{2}$ \\
\hline$a$ & & & $e$ & \\
\hline $\mathrm{A}_{2}$ & & $\mathrm{E}_{3}$ & & $\mathrm{E}_{4}$ \\
\hline
\end{tabular}

In the Erfurt manuscript:

$e=\mathrm{E}_{1}+\frac{a-\mathrm{A}_{1}}{\mathrm{~A}_{2}-\mathrm{A}_{1}} \times\left(\mathrm{E}_{3}-\mathrm{E}_{1}\right)+\frac{c-\mathrm{C}_{1}}{\mathrm{C}_{2}-\mathrm{C}_{1}} \times\left(\mathrm{E}_{2}-\mathrm{E}_{1}\right)+\frac{a-\mathrm{A}_{1}}{\mathrm{~A}_{2}-\mathrm{A}_{1}} \frac{c-\mathrm{C}_{1}}{\mathrm{C}_{2}-\mathrm{C}_{1}} \times\left(\mathrm{E}_{2}-\mathrm{E}_{3}\right)$.

In the Paris manuscripts:

$$
e=\mathrm{E}_{1}+\frac{a-\mathrm{A}_{1}}{\mathrm{~A}_{2}-\mathrm{A}_{1}} \times\left(\mathrm{E}_{3}-\mathrm{E}_{1}\right)+\frac{c-\mathrm{C}_{1}}{\mathrm{C}_{2}-\mathrm{C}_{1}} \times\left(\mathrm{E}_{2}-\mathrm{E}_{1}\right) .
$$

Here also two simple remarks are in order:

(1) The simple algorithm is the same in both texts, it would stand as the basic double entry table interpolation procedure and seems a straightforward adaptation of the simple entry table interpolation algorithm.

\footnotetext{
${ }^{3} \mathrm{BnF}$, lat. 7281 f. $201 \mathrm{v}-205 \mathrm{v}$; BnF lat. 10263 f. 70r-78r; Erfurt $4^{\circ} 366$ f. $28 \mathrm{r}-32 \mathrm{v}$.
} 
(2) The more complex algorithm is present only in the older manuscript, and seems to be some sort of an unessential part of the work to its reader since it can apparently be modified without justification or even mention. This last remark is of importance not as a value judgment on the poor respect paid by ancients to the author of the text ${ }^{4}$, but rather because it points to a certain autonomy of the interpolation techniques from the tables to which they are attached.

What can we learn from these examples? If we consider tables as some special sort of text we can add to the remarks that were already made that the algorithm influence also the setting of tables in which difference columns are added in order to speed up the interpolation process.

Concerning the mathematical aspects of tables, we first need to say that at the core of any interpolation procedure is the belief that there are some values between the entries of the table. Thus the discrete setting of tables (because of the discrete grid and because of the use of numbers) is conceived as something continuous. Interpolation is one of the bridge between magnitude and multitude. It notably results in work with the concept of sexagesimal numbers and on units. These complex interpolation procedures are also a locus for experimentation of long arithmetical computation with positive or negative numbers which were unknown at the time in other branches of mathematics. Lastly these interpolation procedures are also one important aspect of the tabular way to represent relation in the conceptual "tool box" of ancient mathematics. In the long term it will stay an important part of the function concept and even later of numerical and functional analysis.

Finally examining the interpolation procedure closely may be a way to address sociological aspect of the uses of tables. Interpolation procedures are part of both the production and use of astronomical tables: if we are able to compare both sets of interpolation techniques we may have evidence concerning the mathematical education of users and makers of tables at different times and places. The examples of Ligneris and Muris tables of equation are also informative in this respect. The complex interpolation procedure is present in the older manuscript which comes directly from the peers of John of Saxony, himself a great astronomer, while the simpler algorithm comes from manuscript circulating in a totally different milieu of humanist publishers. This is not a question of time because Muris interpolation procedures are not simplified by the 15th century astronomers who have transmitted us the text.

\section{REFERENCES}

[1] J. Chabás and B. R. Goldstein, Computational astronomy: five centuries of finding the true syzygy, Journal for the History of Astronomy 28(2) (1997), 93-105.

[2] B. Porrez and J. Chabas, John of Murs's Tabula permanentes for finding true syzygies, Journal for the History of Astronomy 32(1) (2001), 63-72.

\footnotetext{
${ }^{4}$ Such a remark would in fact be meaningless because there is no such thing as a modern author during these medieval periods.
} 


\title{
Al-Samaw'al and his unusual Sine table: Innovation or academic fraud?
}

\author{
Glen Van Brummelen
}

Al-Samaw'al ibn Yahya al-Maghribī, a 12th century Iranian scientist best known for his contributions to algebra, also wrote an inflammatory treatise near the end of his life entitled Kashf'unwar al-munajiimin, or Exposure of the Errors of the Astronomers. In this work he castigates his astronomical colleagues and predecessors for a variety of academic sins and proposes various solutions. A central theme throughout the book is a methodological insistence on complete precision when geometrical methods are called upon. Any use of approximation, whether or not it makes any practical astronomical difference, is condemned and an alternate argument proposed.

The fourth section of Errors of the Astronomers deals with the computation of chord and sine tables. The standard method, established in Book I of Claudius Ptolemy's Almagest, works as follows (translated from Ptolemy's chords into sines): begin with the values that may be found easily by geometric means, namely, $\sin 18^{\circ}, \sin 30^{\circ}, \sin 36^{\circ}$, and $\sin 45^{\circ}$. Then apply the sine addition and subtraction laws, the sine half-angle formula, and the Pythagorean Theorem (to find sines of arcs for which the sines of their complements are known). This leads to values for the sines of every multiple of $3^{\circ}$. To go further to the sines of all multiples of $1^{\circ}$ requires the use of an approximation. If $\alpha>\beta$, then

$$
\frac{\alpha}{\beta}>\frac{\sin \alpha}{\sin \beta} ;
$$

inserting $\left(\alpha=3 / 2^{\circ}, \beta=1^{\circ}\right)$ and $\left(\alpha=1^{\circ}, \beta=3 / 4^{\circ}\right)$ provides reasonably tight upper and lower bounds for $\sin 1^{\circ}$.

Although various enhancements to this basic scheme were conceived by Islamic astronomers, all of them require an approximation to find sines beyond the multiples of $3^{\circ}$, and it is this to which Samaw'al objects. His solution is to redefine the number of units in a circle, from $360^{\circ}$ to 480 parts. In this way the geometrically accessible $\sin 3^{\circ}$ becomes $\sin 4$. Apply the half-angle formula twice and we have $\sin 1$. From this value, all sines of whole-numbered arcs can be constructed. This is in fact the only table Samaw'al presents in his book.

Examination of the entries of the table, however, reveals that Samaw'al did not actually apply this method. Every fourth entry is taken directly from a conventional sine table, and his other entries are interpolated from all the entries in that table. So three quarters of Samaw'al's sine values rely on the values that were approximated in the conventional table. Further, he goes on to critique other astronomers using calculations that themselves rely on this table.

On the surface, this would appear to render Samaw'al guilty of academic hypocrisy. But is this accusation justified, or is it an anachronistic modern judgment of a historical period that would have treated the matter differently? Tables in medieval Islam were frequently copied from one work to the other apparently without 
any sense of wrong. The academic culture of the table-makers themselves is almost completely unknown, since most of their activity was unrecorded except indirectly, in the tabular entries. It does seem difficult to apply historical sensitivity in Samaw'al's defense, since he seems to be guilty of the same crime of which he explicitly condemns his colleagues. In general, however, we must leave open the possibility that table makers had different standards by which their work was judged.

\section{REFERENCES}

[1] A. Aaboe, Al-Kāshī's iteration method for the determination of $\sin 1^{\circ}$, Scripta Mathematica 20 (1954), 24-29.

[2] J. L. Berggren and G. Van Brummelen, Al-Samaw'al versus al-Kūhī on the depression of the horizon, Centaurus 45 (2003), 116-129.

[3] G. Van Brummelen, The Mathematics of the Heavens and the Earth: The Early History of Trigonometry, Princeton, NJ: Princeton University Press, 2009.

\section{Napier revisited or A further look at the computation of his logarithms}

JOACHIM FISCHER

(joint work with Bärbel Ruess)

John Napier (1550-1617) introduced logarithms into mathematics when he published his Mirifici canonis logarithmorum descriptio in 1614 [3]. A more detailed presentation of the underlying ideas and the construction of a table of logarithms were posthumously published as the Mirifici canonis logarithmorum constructio in 1619 [4]. Using modern notions and notation, while at the same time trying to respect what Napier actually says, does or means, one here finds that he describes a function $\mathrm{LN}(x)=h \cdot \ln (h / x)$, where LN stands for Logarithmus Neperiensis or Napierian Logarithm, $h=10^{7}$, and ln has the usual meaning. In the interval $[0, h]$ $\mathrm{LN}$ is monotonically decreasing from $\mathrm{LN}(0)=\infty$ to $\operatorname{LN}(h)=0$. (If $h$ were 1 , we would have $\mathrm{LN}(x)=\ln (1 / x)$, and this $\mathrm{LN}$ would immediately be recognisable as our logarithm to base $e^{-1}$.)

As $\operatorname{LN}(a \cdot b)=\mathrm{LN}(a)+\mathrm{LN}(b)-h \cdot \ln (h)$ and $h \neq 1$, there is no logarithmic functional equation for LN $\operatorname{like} \log (a \cdot b)=\log (a)+\log (b)$. Instead Napier found $\mathrm{LN}(a)-\mathrm{LN}(b)=\mathrm{LN}(u)-\mathrm{LN}(v)$, if $a: b=u: v$ (implicitly requiring $0<a<b \leq h$, $0<u<v \leq h$ in order to avoid negative numbers and to stay in the range $(0, h]$, 0 excepted in this case). This was even better suited than a functional equation for Napier and his contemporaries, because they were accustomed to calculating in proportions.

For LN to be useful in replacing multiplication by addition etc., a table of LN is needed; and for practical reasons Napier decided to tabulate $\operatorname{LN}(x)$ for the sines of the angles $\alpha$ in the first quadrant, $\alpha=0^{\circ} 0^{\prime}\left(1^{\prime}\right) 90^{\circ} 0^{\prime}$. In Napier's times such sine values were tabulated as natural numbers, in many cases resulting from a radius of $h=10^{7}$. If we designate sines of this kind as SIN, then up to rounding we have 
$\operatorname{SIN}(\alpha)=h \cdot \sin (\alpha)$; consequently we have $\operatorname{LN}(\operatorname{SIN}(\alpha))=-h \cdot \ln (\sin (\alpha))$, underlining the role of $h$ as a mere scaling factor. Napier's aim thus was to compute a table of 5401 values $\operatorname{LN}(\operatorname{SIN}(\alpha))$, from $\operatorname{LN}\left(\operatorname{SIN}\left(0^{\circ} 0^{\prime}\right)\right)=\infty$ to $\operatorname{LN}\left(\operatorname{SIN}\left(90^{\circ} 0^{\prime}\right)\right)=0$.

Except for the table given by Napier himself in 1614, there are only two other independently computed tables of LN, one given by Johannes Kepler (1624, using $h=10^{5}$ ) and the other by Benjamin Ursinus $\left(1625, h=10^{8}\right)$. But as LN was almost immediately superseded by Briggsian (or decimal) logarithms, there hasn't been too much interest in how Napier's calculations were really done. Thus it has escaped - for almost 400 years now - that Napier developed several ingenious numerical ideas and procedures, ranging from the first elements of interval arithmetic (usually traced back only to the 1930s!) to the forward analysis of the propagation of (rounding and/or truncating) errors. Considering that nothing was known about LN's values except $\mathrm{LN}(0)=\infty$ and $\mathrm{LN}(h)=0$, it should have been obvious that Napier, being the first to construct an LN table, must have found the means to circumvent a lot of difficulties. Especially when one appreciates that he intended his table to have a maximal error of one unit in the last place of the LNs given, while at the same time he had no other values at his disposal except the two just mentioned, one should have become interested in his procedures - the more so, as he obviously succeeded in solving the problems.

In 1997 and 1998 one of us ([1], [2]) offered a reconstruction of some of Napier's ideas, of which we only see the results in the Constructio and the Descriptio, but not the ways in which they might have been developed. In the Oberwolfach talk, based on numerical data provided by the other of us, we had a closer look into the calculations themselves. As Napier had at least four methods of computing LNs in the interval $[0, h]$, but none of them valid for the whole interval, we tried to show when and why he switched from one method to the other; and at the same time we were able to reassess previous speculations about the SIN table(s) used by Napier. Further work is still necessary and will hopefully end in an even complete synthesis of the reconstructive results which were obtained so far.

\section{REFERENCES}

[1] J. Fischer, Looking "behind" the Slide Rule: How did Napier compute his Logarithms?, Proceedings of [the] Third International Meeting of Slide Rule Collectors, September 12, 1997, Faber-Castell Castle, Stein/Nürnberg, 8-18 [a substantially enlarged version is available at www.rechnerlexikon.de/files/LogNapier-F.pdf, in German only].

[2] J. Fischer, Napier and the Computation of Logarithms, Journal of the Oughtred Society $\mathbf{7 ( 1 )}$ (1998), 11-16.

[3] J. Napier, MIRIFICI Logarithmorum Canonis descriptio, Ejusque usus, in utraque Trigonometria; ut etiam in omni Logistica Mathematica, Amplissimi, Facillimi, $\&$ expeditißimi explicatio. Authore ac Inventore, IOANNE NEPERO, Barone Merchistonii, Ec. Scoto, Edinburgh: A. Hart, 1614.

[4] J. Napier, MIRIFICI LOGARITHMORVM CANONIS CONSTRVCTIO; Et eorum ad naturales ipsorum numeros habitudines; VNÀ CVM Appendice, de aliâ eâque præstantiore Logarithmorum specie condenda. QVIBVS ACCESSERE Propositiones ad triangula sphærica faciliore calculo resolvenda: Vnà cum Annotationibus aliquot doctissimi D. HENRICI BRIGGII, in eas \& memoratam appendicem. Authore $\mathcal{E}$ Inventore Ioanne Nepero, Barone Merchistonii, Ecc. Scoto, Edinburgh: A. Hart, 1619. 


\section{For what kind of tables Charles Babbage's "Difference Engine" and "Analytical Engine" were conceived? \\ MARIE-José DURAnd-RICHARD}

This contribution is intended to delineate the project's chapter dedicated to the mechanization of tables, and the questions opened by this issue. This topic is a transversal one, and will also comprehend information from other subgroups. It crosses the 19th and the 20th century, essentially through the industrialization process, and it meets digital devices as well as analog ones, and explores how and why they were respectively thought of and constructed or not.

Beginning to explore this subject first leads back to Babbage's Difference and Analytical Engines, in order to understand better the relationships between the mathematical and the mechanical works of their inventor, and the correlations between his ways of thinking about functions, tables and machines. The mechanical organizational structures of these two engines will not be revisited here, as they were very well described by various authors ([10], [8], [6]). Nevertheless, we could remember that:

- for the Difference Engine, a first little model, with two orders of differences, was built in 1822. Then, the construction of a bigger machine was planned, and partially realized, with funding from both Babbage and the government, but it was never achieved. Only a nice model with two orders of differences was mounted in 1842. Babbage's revised plan, elaborated in the 1850s, was finally achieved by the Science Museum of London in 1991.

- for the Analytical Engine, pieces for the machine were realized, but never completely assembled. But numerous contemporaneous plans, explanations, and some reviews exist.

Main sources of interest for the method of differences in the 1810s' England. Charles Babbage (1791-1871) conceived of the Difference Engine when he created the Astronomical Society in 1820, together with John F. W. Herschel (1791-1871) and a group considered as "business astronomers" - because they initially worked as actuaries- such as Henry T. Colebrooke (1765-1827) and Francis Baily (1774-1844). He walked in the footsteps of De Prony's Great Tables, calculated in France when the decimal system was adopted, and when "grades" replaced degrees for measuring angles.

In fact, both Babbage and Herschel had first become interested in the method of differences ten years before, when they collaborated to introduce the differential notation in the differential calculus in Cambridge, in order that Laplace's Mécanique Céleste could be largely readable in England. From 1813 - with their collective publication of the Memoirs of the Analytical Society - to 1820, Herschel carried out numerous new investigations on equations of finite differences, paying a special attention to the operative properties of the functional notation, and of the symbol $D=\frac{d}{d x}$, considered as a "symbol for an operation".

In all these papers, as well as those of Lagrange and Laplace, powers series were considered as an extension of algebraic polynomials. Every unknown function 
was thought of as expandable in an infinite series, so that an investigation of the properties of the first coefficients of the series could afford an approximate solution of the equation. And conversely, any infinite series was contemplated as the expansion of a function, even if no analytical form was known for it. The separation of symbols for operations from symbols for quantities was also at the core of Babbage's thought on the organizational structure of the Difference Engine.

A huge comprehensive plan of tables computations. In 1823, Baily presented all the fields of computations where tables were involved: numerical tables, tables for astronomy and navigation, and tables for interests and annuities tables. He proceeded as if the Difference Engine abolished the distinction between exact and approximating tables, so that the uniformity of the mode of computing contributed to the standardization of the whole range of numbers and tables. Moreover, this engine opened the way to the discovery of new functions, without known analytical form. For Baily, Colebrooke and Babbage, the Difference Engine allowed the launch of a new program of computing tables, because all these tables were reducible to method of differences. In this period where making tables was still an handwork activity, they intended to make it a manufactured one. What were at stake were the conditions of this transformation.

What is changing between the Difference and the Analytical Engine. Clearly, the Difference Engine was a special type of engine, whose initial settings induced the computations for a particular table. But the Analytical Engine was a universal machine, "adapted for developing and tabulating any function whatever". So it could obtain numerical results - expressed by decimal fractions - for any function defined by a series, that is, for Babbage, for the whole analysis. Moreover, Ada Lovelace, when she translated in English the French Menabrea's presentation of the machine [9], insisted on the fact that the machine was essentially fitted for analytical calculations on general symbols, and could give therefore symbolical results.

Conclusive remarks on Babbage's heritage. In spite of Babbage's interest for the world of manufacturers, the relationships between the academic world and the engineers' one would have to be investigated more in order to understand why in 1876, Lord Kelvin, and in 1934, Douglas Hartree, succeeded in constructing respectively the harmonic analyzer and the differential analyzer, the former to analyze tides and the latter to give numerical solutions for differential equations, involving private firms in their enterprises. To be introduced in the whole domain of computing tables, they also had to navigate the social organization of computations in several professional contexts.

It will also be necessary to investigate the relationship between the mechanization of tables and the respective importance of the general view of function, which changed consistently from Cauchy's approach, with the distinction between discrete and continuous realms, and the respective importance of numerical and theoretical analysis. 


\title{
REFERENCES
}

[1] Cambridge Analytical Society, Memoirs of the Analytical Society, Cambridge, 1813.

[2] W. J. Ashworth, The calculating eye: Baily, Herschel, Babbage and the business of astronomy, The British Journal for the History of Science 27 (1994), 409-441.

[3] F. Baily, On Mr Babbage's new machine for calculating and printing mathematical and astronomical tables, Astronomische Nachrichten 46 (1823), 409-422. Reprint in The Works of Charles Babbage, vol. 2, 1989, 44-68.

[4] M. Campbell-Kelly (ed.), The Works of Charles Babbage, 11 vol., London: Pickering, 1989.

[5] H. T. Colebrooke, Address on presenting the Gold Medal of the Astronomical Society to Charles Babbage, Memoirs of the Astronomical Society 1 (1825), 509-512. Reprint in The Works of Charles Babbage, vol. 2, 1989, 57-60.

[6] J. M. Dubbey, The Mathematical Work of Charles Babbage, Cambridge: Univ. Press, 1978.

[7] M. J. Durand-Richard, Charles Babbage (1791-1871): De l'École algébrique anglaise à la "machine analytique", Mathématiques, Informatique et Sciences humaines 118 (1992), 531; Erratum, 120 (1992), 79-82.

[8] A. Hyman, Charles Babbage, Pioneer of the Computer, Princeton, NJ: Princeton University Press, 1983.

[9] L. F. Menabrea, Notions sur la machine analytique de M. Charles Babbage, Bibliothèque universelle de Genève (nouvelle série) 41 (1842), 352-376. Translated by A. A. Lovelace, Sketch of the Analytical Engine invented by Charles Babbage, Scientific Memoirs 3 (1843), 666-731. Reprint in The Works of Charles Babbage, vol. 3, 1989, 62-170.

[10] D. Swade, Charles Babbage's Difference Engine $n^{\circ}$ 2, Science Museum Papers on the History of Technology 4 (1995).

\section{Survey of graphical and numerical tables in Egypt}

\author{
MicAH T. Ross
}

At the XXIII International Congress of History of Science and Technology, a reductive approach clarified the corpus of Egyptian numerical tables. More recently, paleographical methods have illustrated a potential definition of Egyptian numerical tables. Recourse to informatic definitions provides yet another definition: tables order information by rows and columns.

In some cases, the rows and columns of the table may be used to generate information. The information generated in a table derives from transforming the elements of a row or column. For example, PCarlsberg 32 contains a column for the daily motion of Mercury $(A)$ and a column for the displacement for Mercury from its maximal elongation $(B)$, where $A_{n}=n \times 0 ; 05,27,17$ and $B_{n}=B_{n-1}+A_{n}[1]$. In this way, all the values of table are generated from a single parameter. In order to transform this value into an astronomically useful result, the values of this table may have been used in conjunction with another type of table. Likewise, the method of multiplying in Egypt involved the construction of a table which contained successive doublings of the multiplicand until the multiplier may be summed up from the powers of two. The consideration of every multiplication as a table is impractical, but the identification of tables with information generation represents an important use of tables in Egypt.

Alternately, the rows and columns can simply order information produced elsewhere. In this way, the table serves as a means of organizing and displaying 
information. For example, the Stobart Tablets formed an "analog spreadsheet": at least nine wooden tablets, divided into five columns and 29 to 33 rows, marked the date of the entries of the planets into zodiacal signs [2]. The ordering of the planets and the astronomical events conforms more closely to the genre of list than table. Although true tables may also be used for information display, such "table-like arrays" are more adaptable and form the larger number of examples of information display.

The two genres may be compared: truly tabular texts defined by the argument between the two indexes are somewhat uncommon in Egypt. The best known examples of Egyptian numeric tables are fraction tables. Unlike the tables, tablelike enumerations lack an argument between the index and the variables. Such texts are common in Egypt, but the best-known examples are non-numeric. The establishment of an index forms an important point in the analysis of a table. For example, P. CtYBR inv. 1132(B) forms a tabular array of three rows by four columns [3]. Each cell contains information about a zodiacal sign. This papyrus has previously been interpreted as implying an Egyptian awareness of the astrological doctrine of triplicities. However, any tabular arrangement would conform to some astrological doctrine, be it opposition, trine, quadrature, or sextile aspect. Thus, the dimensions of the table - as well as possible implicit indexing - must be carefully considered.

The graphical tables used in Egyptian star clocks present an interesting middle ground between the two approaches [4]. First, the measurement of the stellar position with reference to bodily measurements challenges a strict defintion of numeric tables, but even overlooking this difficulty, the tables challenge classification. Because the horizontal axis represents successive portions of the ecliptic and the vertical axis represents time, the table lacks a true index and forms a (possibly compressed) list. As a further complication, some scribes working in this genre have indicated vertical displacement from some line by vertical displacement on the temporal axis.

The story of Egyptian numeric tables has not yet been definitively written. At least one new fraction table will be published in the next year. This fraction table is closely linked with the generation of information. In fact, the table is found in a series which culminates with OMM 251, an educational text which works an example of how to cast a horoscope for 154 A.D. [5].

\section{REFERENCES}

[1] R. Parker, Two Demotic astronomical papyri in the Carlsberg collection, Acta Orientalia 26 (1962), 143-147.

[2] O. Neugebauer, Egyptian Planetary Texts, Transactions of the American Philosophical Society 32(2) (1942), 205-250.

[3] L. Depuydt, A Demotic Table of Terms, Enchoria 21 (1994), 1-9.

[4] O. Neugebauer and R. Parker, Egyptian Astronomical Texts, 2: The Ramesside Star Clocks, Brown Egyptological Studies 5 (1964), passim.

[5] M. Ross, Conclusion to the Horoscopic Texts of Medinet Madi, Egitto e Vicino Oriente 33 (2011), forthcoming. 


\title{
On the nature of the table Plimpton 322
}

\author{
Christine Proust
}

The cuneiform tablet Plimpton 322 (P322 in the following) is generally understood to be a table providing 15 Pythagorean triples. This document is the best known and the most controversial of the cuneiform mathematical texts. Various interpretations of the text were offered by many scholars ([8], [2], [9], [5], [10], etc.), the last one being provided by the forthcoming article by J. Britton, C. Proust and S. Shnider [1]. The various interpretations rely on different assumptions about the very nature of the text. What kind of table is P322?

The provenance of the tablet is unknown. Edward Banks, the dealer who sold the tablet to the collector George Plimpton in 1922 or 1923, claimed that the tablet was found in Larsa in southern Mesopotamia. Epigraphic evidence shows that the tablet dates from the Old Babylonian period, that is, the early second millennium BC. P322 is an atypical mathematical tablet which presents features that are not observed in any other mathematical document: landscape orientation, tabular format with horizontal and vertical lines, heading of columns and numbered rows. The tablet is inscribed on the obverse. The reverse is uninscribed, but the vertical lines of the obverse are extended on the reverse. The left part, representing about a third of the original tablet, is lost. The preserved text is made of four columns with headings, and 15 rows of numbers written in place value notation, without indication of the order of magnitude ("floating notation").

The heading of column I runs as follows: "the square of the diagonal from which 1 is subtracted and that of the width comes up". This can be expressed, in modern notation, as: $\delta^{2}-1^{2}=\beta^{2}$, where $\delta$ is the diagonal of a rectangle, and $\beta$ is the width. For example, the first row of column I contains the number 1,59,0,15. This number is noteworthy: first, it is a finite sexagesimal square number (the square of 1,24,30); second, if 1 , the first digit, is subtracted from $1,59,0,15$, the number obtained is 59,0,15 (the square of 59,30). Thus the number $1,59,0,15$ alone provides a Pythagorean triple or, to use a less anachronistic concept, a "sexagesimal rectangle". The first column contains 15 square numbers, providing 15 sexagesimals rectangles.

In the headings of columns II and III, we read: "the side width" $(b)$ and "the side diagonal" $(d)$. The data of these columns correspond to sexagesimal rectangles (in each row, $d^{2}-b^{2}$ is a square number), similar to the ones given in column I. For example, the values given in the first row are 1,59 and 2,49. The rectangle of which the width is 1,59 and the diagonal 2,49 is similar to the rectangle obtained from column I (width 59,30 and diagonal 1,24,30).

Column IV contains the numbering of the lines (ki1, ki 2, etc. = place 1, place 2 , etc.), with the heading: "Its lines are".

Thus, the tablet provides a list of 15 sexagesimal rectangles. Each row contains two similar rectangles: the first is a unit rectangle, that is, a rectangle which length is 1 ; the second is a reduced rectangle, that is, a rectangle whose dimensions admit no regular common factor. The interpretative problems raised by P322 could be summarized into two questions: 
(1) What is the horizontal reading? Namely: are the successive columns generated by a unique algorithm?

(2) What is the vertical reading? Namely: are the successive rows generated by a unique algorithm?

These questions were answered by historians in different ways according to the supposed function assigned to the table. For Neugebauer and Sachs, P322 is a problem text, for Robson, it is a teaching aid, and for Friberg, it is halfway between ([8], 41; [10], 199, 201; [5], 302; [6], 448). The forthcoming publication by Britton, Proust and Shnider, based on new texts published and interpreted by Friberg, revives the point of view of Neugebauer and Sachs in considering P322 as a problem text. Here are some arguments supporting this latter interpretation.

In the present short paper, I shall limit myself to emphasizing some aspects concerning the vertical reading. The question is: are the 15 rows the result of a unique algorithm? This problem was solved as early as 1964 by Price who observed that the lines drawn on the obverse of the tablet continue on the lower edge and the reverse of the tablet. Thus, the 15 preserved rows are, in fact, the first 15 rows of a bigger table. Probably, the scribe planned to compose between 30 and 40 rows. In addition Price assumed that the width of the rectangle was shorter than the length, and that the numbers involved belong to the usual repertoire of the time, that is, 1 or 2-place value regular sexagesimals numbers. For Price, as for Neugebauer and Sachs, the algorithm for producing the sexagesimals rectangles used generative numbers $s$ and $r$, and could be described by the following formulae:

$$
\delta=\frac{1}{2}\left(\frac{r}{s}+\frac{s}{r}\right), \quad \beta=\frac{1}{2}\left(\frac{r}{s}-\frac{s}{r}\right) .
$$

Price searched for all the numbers $r$ and $s$ satisfying the following conditions:

- $1<\frac{r}{s}<1+\sqrt{2}$

- $r$ is a regular sexagesimal number

- $s$ is a 1-place value regular sexagesimal number

- $\frac{r}{s}$ is irreducible.

He found 38 pairs $r, s$, among them the 15 first produced the 15 rectangles preserved on column I. This is a very strong result. It shows that the 15 rows of P322 were indeed generated by a systematic algorithm, and, moreover, offers a credible reconstruction of the whole text, including the unfinished part of the reverse (see [1] for more details).

But the Price's reasoning is based on modern concepts, such as irreducible fraction and inequalities, which are alien to contemporary Babylonian mathematical culture. What sort of tools were available to the scribes in the Old Babylonian period? It is well known that, as soon as in their elementary stage of education, the scribes were trained to work on lists and tables, in particular, reciprocal tables. Thus, the scribes probably used a list of reciprocal pairs, corresponding to the Price's list of ratios $\frac{r}{s}$ and $\frac{s}{r}$. The numbers the more often used in scribal schools were the 1-place value regular numbers, as well as the 2 -place values numbers until 2,5 , that is the following list of numbers: 
$\{1\},\{2\},\{3\},\{4\},\{5\},\{6\},\{8\},\{9\},\{10\},\{12\},\{15\},\{16\},\{18\},\{20\},\{24\}$, $\{25\},\{27\},\{30\},\{32\},\{36\},\{40\},\{45\},\{48\},\{50\},\{54\},\{1,4\},\{1,12\},\{1,15\}$, $\{1,20\},\{1,21\},\{1,30\},\{1,36\},\{1,40\},\{1,48\},\{2\},\{2,5\}$ (list A).

The set of all the quotients obtained by dividing numbers of list $A$ by the 1-place value regular numbers is a long list containing many duplicates. After removing the duplicates from this long list, ordering it in lexicographic order, selecting the numbers between 1 and $1+\sqrt{2}$ (that is, between 1 and 2,25), and rearranging in descending order, we obtain the following list:

$\{2,24\},\{2,22,13,20\},\{2,20,37,30\},\{2,18,53,20\},\{2,15\},\{2,13,20\}$, $\{2,9,36\},\{2,8\},\{2,5\},\{2,1,30\},\{2\},\{1,55,12\},\{1,52,30\},\{1,51,6,40\}$, $\{\mathbf{1}, \mathbf{4 8}\},\{1,46,40\},\{1,41,15\},\{1,40\},\{1,37,12\},\{1,36\},\{1,33,45\},\{1,30\}$, $\{1,28,53,20\},\{1,26,24\},\{1,25,20\},\{1,24,22,30\},\{1,23,20\},\{1,21\},\{1,20\}$, $\{1,16,48\},\{1,15\},\{1,12\},\{1,11,6,40\},\{1,7,30\},\{1,6,40\},\{1,4,48\},\{1,4\},\{1,2,30\}$.

This is exactly the values of $\frac{r}{s}$ obtained by Price. The 15 first values (in bold above) generate the 15 rows of P322. Thus, using only tools known by ancient scribes, we obtain the list of reciprocal pairs generating the extended table. This reconstruction of the possible ancient modus operandi supports the hypothesis that the author of P322 was looking for an exhaustive list of solutions.

Let us conclude with some remarks on the nature of the text and on the meaning of the tabular format. P322 appears to be an attempt to find all the finite sexagesimal rectangles. According to the text MS 3972 \#3 published by Friberg in 2007, the problem could be formulated as: "In order for you to see all the diagonals". The tentative to "see all the diagonals" is successful if we accept some restrictions linked to Old Babylonian calculation practices, such as the use of standard table of reciprocals. Thus, P322 seems to be a procedure text and not an aid or a document providing data for various uses (teaching or other).

What is the meaning of the tabular format? The mathematical content of P322 is similar to the third problem of the non tabular text MS 3972 \#3. The structure of the information is the same in both texts, as well as the indexing with "ki 1", "ki 2", etc. Why is the first text tabular, but the second is not? In the Plimpton table, the information is decomposed into elements, and these elements of information are classified and rearranged: the items of the same nature occupy the same column. The general names of these elements are noted in the heading. Thus, the information is compressed, and the headings appear to be a general formulation of the individual rows. Likewise, the tabular format underlines the exhaustive character of the list. To conclude, P322 seems to be the beginning of a complete set of solutions of an indeterminate problem.

\section{REFERENCES}

[1] J. P. Britton, C. Proust and S. Shnider, Plimpton 322: A review and a different perspective, Archive for History of Exact Sciences (2011).

[2] E. Bruins, On Plimpton 322. Pythagorean numbers in Babylonian mathematics, Indagationes Mathematicae 11 (1949), 191-194. 
[3] E. Bruins, Pythagorean triads in Babylonian mathematics; the errors in Plimpton 322, Sumer 11 (1955), 44-49.

[4] CDLI (website), Cuneiform Digital Library Initiative, http://cdli.ucla.edu/.

[5] J. Friberg, Methods and traditions of Babylonian mathematics: Plimpton 322, Historia Mathematica 8 (1981), 277-318.

[6] J. Friberg, A Remarkable Collection of Babylonian Mathematical Texts, New York: Springer, 2007.

[7] A. Jones and C. Proust, Before Pythagoras: The Culture of Old Babylonian Mathematics, ed. J. Chi.

[8] O. Neugebauer and A. J. Sachs, Mathematical Cuneiform Texts, New Haven: AOS and ASOR, 1945.

[9] D. Price and J. de Solla, The Babylonian "Pythagorean triangle" tablet, Centaurus 10 (1964), 219-231.

[10] E. Robson, Neither Sherlock Holmes nor Babylon: A reassessment of Plimpton 322, Historia Mathematica 28 (2001), 167-206.

\title{
Composing material for the HTN book after the IMERA International Workshop on Numerical Tables in Sanskrit
}

\author{
Agathe Keller
}

A great variety of numerical tables can be found in the Indian sub-continent. In the HTN project we restrict ourselves to Sanskrit tables dating roughly from the Common Era to the XVIIIth century.

Different kinds of mathematical objects are qualified as "tables" by historians of mathematics working on Indian sources: verbally coded, sometimes versified, lists of numerical data (Sines, for instance), astral tables-texts of the $z \bar{\imath} j$-type, verses defining different types of measuring units (if we agree that these are not just lists), and computational arrays. A general bird's eye view of astronomical tables in Sanskrit sources was made possible by an HTN funded workshop held from the 13th to the 15th December 2010 at the IMERA in Marseille. Three main strands were highlighted: south Indian traditions of numerical tables, astronomical table-texts, and a long pan-Indian evolution of Sine and Sine difference tables.

Indian astronomical tables do not contain planetary observations. They concern computed positions of planets generally in relation to a given epoch and typically compute the times and dates of transits of planets in mean or true longitude. This is notably the case of the south Indian vākyas studied by M. Koolakkodlu; a kind of numerical table, coding numerical data with the help of the katapayādi notation which enables lists of numbers to be given in sentences that also have a non-numeral meaning. V. Pai and R. Sharma worked on the XVth century Sanskrit Karanapaddhati of Putumana Somayājī with its anonymous and undated Malayalam commentary. This text provides algorithms to derive and modify parameters used in the Vth century Áryabhatīya of Aryabhata, to find better true and mean longitudes for planets by applying corrections to existing procedures, and to produce tables of solar transit. The edition of the text shows a great variety of formal displays intertwined with verbal codings of numbers, questioning what can be found in manuscripts. 
Astronomical table-texts were studied by K. Plofker and C. Montelle, heading a project on computational procedures and Sanskrit tables in the second millennium. These "table-texts" consist mainly of laid-out tabulated data with versified instructions. The effective astronomical contents of the texts relating to D. Pingree's classification of planetary, almanac, eclipse and geographical tables were discussed. While south Indian verbal tables were either called vākya "sentence" or labelled - as enumerations usually are - by suffixing the first with a $d i$ ("etc."), astronomical table-texts could be called sarani (path) or koșthaka (granary).

I studied two numerical tables classified on the fringes of astronomy and mathematics. First, I considered the versified solutions of a first degree Diophantine linear equation provided by Bhāskara, a VIIth century astronomer commentator of Āryabhața. Bhāskara's shortcut in a "pulverizer" (kuttakāra) process attempting to find the smallest solutions of $y=\frac{a x \pm c}{b}$ consists in solving first the problem when $c=1$, that is:

$$
y=\frac{a x \pm 1}{b}
$$

The values found as solution can then be multiplied by $c$; smallest solutions are found by considering the remainders of the divisions of $c y^{\prime}$ by $a$ and $c x^{\prime}$ by $b$. This is known in later literature as the sthirakuttaka, "lasting pulverizer". Such a procedure could solve an astronomical problem: If $a_{p}$ is the number of revolutions of a given planet $p$, during a yuga time cycle, and $b$ "the number of conjunctions of the planet with the earth" during a yuga (these are fixed parameters), and if $y_{p}$ is the number of revolutions made by a given planet in $x$ days computed from a given epoch (ahargana), the assumption is that

$$
\frac{y_{p}}{a_{p}}=\frac{x}{b}
$$

Usually only a fractional part of $y_{p}$ is known: the mean longitude of the planet. The remaining part, $y$, is unknown, together with $x$.

After explaining the pulverizer, Bhāskara gives 91 ślokas: values obtained from a "lasting pulverizer" provide the number of civil days and the number of revolutions since the beginning of the kali-yuga for the Sun, the Moon, the Moon's Apogee, the Moon's ascending node, Mars, Mercury, Jupiter, Venus, Saturn, the Moon's Anomaly. Other computed elements concern intercalary months, intercalary days, omitted days and the sun's declination. These versified tables are implicitly indexed by $b$ and $a_{p}$, measured in revolutions, signs, degrees, minutes, etc. The data they tabulate can be seen as an intermediary tool when applying a "pulverizer" to astronomical problems. It may also be an exploration of the ratios of the number of revolutions of a planet to the number of days in a yuga.

The history of Sine tables in Sanskrit texts is a very much treated domain: G. Van Brummelen has recently published a synthesis on this topic. M. Mallayya at the workshop presented a continuation of his work published in G. G. Joseph's latest book. He notably looked at the XVIIth century commentator Muniśvara's interpolating processes. Āryabhața's "Sine difference table" is composed with a meaningless verbal code. Implicitly, the argument considers a unit arc of 225'. 
Implicitly also the list of 24 items is made to be read, by summing its terms progressively to obtain different Sines, and summing its terms reversely to obtain Versines. Sūryadeva's XIIth century commentary on this verse insists on the table's double classification: the Sines of the table are used in astronomy but grounded in general mathematics.

Questions raised during the workshop concerned the emergence of the tabletext genre and the nature of astronomical tables: were they practitioner tools or theoretical explorations? A continent of texts was thus uncovered. We do not know the different communities and contexts in which these texts were used. The remaining mathematical numerical tables are comparatively a less important corpus (measuring units, chapters, magic squares...) and play with the limits of what we define as a table.

\section{REFERENCES}

[1] G. Van Brummelen, The Mathematics of the Heavens and the Earth: The Early History of Trigonometry, Princeton, NJ: Princeton University Press, 2009.

[2] G. G. Joseph, A Passage to Infinity, Medieval Indian Mathematics from Kerala and its Impact, Delhi: Sage, 2009.

[3] K. V. Sarma, Āryabhațina of Āryabhața with the commentary of Sūryadeva yajvan, Delhi: INSA, 1976.

\section{Projects and networks of tables in number theory: A proposal for periodization (1600-1960)}

MAARTEN BULLYNCK

Based upon a number of recently published historical articles ([2], [3], [4], [5]) and the materials in [6] and [8], my talk proposed a tentative "periodization" of tables in number theory. Approximately 8 periods could be discerned:

(1) Beginnings of systematic approaches in number theory (1600-1650)

(2) John Pell's project for a factor table to 102,000 (around 1668)

(3) J. H. Lambert's "call for tables" (1770-1820)

(4) Tables for higher arithmetic with the creation of modern number theory as a discipline (around 1800)

(5) Pairwise collaborations: Mathematicians and table makers (19th century)

(6) Systematic organisation: Committees on mathematical tables (1870-1950)

(7) An international network of (amateur-) mathematicians and table-makers (1900-1950)

(8) The journal Mathematical Tables and Other Aids for Computation, its network and the passage into the digital age (1946-...)

Before discussing the criteria (or parameters) used in establishing this periodization, some general remarks on this list are due.

First of all, the first and last periods of this periodization are, as always, the most problematic ones, because they assume a "beginning of" resp. a kind of "closure". Indeed, it should be remarked that some kind of number theory existed 
before the 17th century and that tables played a role in it (see e.g. [1] for "number theory" in the Middle Ages - thanks to M. Husson for pointing this out to me). However, in this periodization, I chose to start with the Modern Period, with the creation of "modern" mathematics (algebra). For the last period, it should be conceived rather as a open-ended period that we cannot yet fully grasp in its characteristics and development (see L. De Mol's abstract for more on this).

Second, although the periods are arranged in chronological order, the periods 5 to 7 are overlapping or even partially synchronous. They can nevertheless be distinguished easily from each other, because they are more or less anchored in specific research communities. The collaborations (period 5) are typical of a German research culture, involving professors at university and gymnasia; the committees (period 6) are typically an Anglo-Saxon way of organization (and it should be remarked the tables in number theory are only a marginal topic for these committees); and the network (period 7) is mainly organized through journals and mobilizes mainly French, Belgian, Dutch table makers as well as English and U.S. table makers. Naturally, this periodization does not exclude that there are persons passing from one category to the other.

Finally, the periodization only takes into account "big tables". "Big" tables can be set apart from "small" tables by their size, of course, but the difference aimed at here goes epistemologically deeper. "Small" tables usually occur within the flow of an article, of a book, and their utilization is confined to the limits of that article or book. "Big" tables, on the other hand, are usually conceived as independent unities, produced for utilization by many mathematicians. Said differently, "small" tables have no independent afterlife, whereas "big" tables have.

I now turn to the criteria or parameters used in this periodization. Two main criteria were established:

(1) the organisation of making the tables;

(2) the relationship of the table with theoretical \& practical knowledge.

The first criterium includes such factors as: what kind of persons were involved, what media of communication were used, what division of labour in making the table was followed. This criterium was paramount in the distinction between periods 5, 6 and 7, but it also helps to differentiate between periods 7 and 8 (division of labour changes with the introduction of the computer), or between periods 1 and 2 (single mathematicians vs. a small group of mathematicians).

The second criterium is more difficult to pin down. In fact, it has two sides, "[theory \& know-how] $\rightarrow$ table", and, "table $\rightarrow$ [theory \& know-how]". The first aspect is the question: how much theoretical and practical background is needed to understand, produce and use the table, or, how much theory and know-how is imminent in the table. This aspect comes especially to the fore in period 4, where the birth of higher arithmetic, amongst many other effects [7], causes new, more theory-driven tables to be calculated. Very often, one finds that a table that needs little theory to understand, later becomes compressed in another format that needs more theory to understand (e.g. the table of decimal periods vs. the table of indices modulo a prime). This could be called "internalization" of theory 
into the table. This is, in general, a recurring process in the history of a specific kind of table.

To enunciate the second, subtler aspect of this criterium more clearly, the (sociological) concept of "projects of action" (borrowed from A. Schutz [9]) is helpful. The idea is that a sequence of actions lays out one or more "projects of action", i.e., it prepares and preempts possible future sequences of action that are sociologically recognizable as such (other people can recognize that you are working towards project X). The extension of "table $\rightarrow$ [theory \& know-how]" then, is the answer to question: how much is the use of the table prefigured, predetermined by the table. For instance, a logarithm table (nowadays) has a well-defined usage and will be used in generally recognizable situations (e.g. long multiplications) that may or may not be identified and explained in the introduction or manual to the table.

For many tables, take a table of indices of 2 modulo a prime, several uses, not all of which known in advance, are possible (in our example, e.g., factorization of certain numbers, solving congruences, calculating Carmichael numbers etc.). For some tables, no well-defined use is apparent, e.g. a table that gives even numbers as the sum of two primes (Goldbach-conjecture). These last kind of tables may be called proper "explorative" tables. In the course of time, tables that once were "explorative" may become determined in use, or even become completely obsolete. This is understandable, since "project of action" is a sociological concept, dependent on time and context. In this periodization, e.g., Lambert's factor table may have had anno 1770 a partial explorative use, helping to establish a systematic "theory of numbers" Lambert had called for. For Legendre and Gauss around 1800 this explorative "project of action" got more focussed and determined when they started counting and analyzing the factor tables to study the distribution of prime numbers. Nowadays then, the usage of a factor table is nearly completely determined and is inserted in generally recognizable actions. This "table $\rightarrow$ [theory $\&$ know-how]" aspect is for the periodization less important than the first criterium and the "[theory \& know-how] $\rightarrow$ table" aspect of the second criterium, however, it may prove of considerable assistance in later historical research that wants to study the insertion of tables into a concrete, historically situated mathematical practice.

\section{REFERENCES}

[1] G. Beaujouan, Par raison de nombres. L'art du calcul et les savoirs scientifiques médiévaux, Aldershot: Variorum, 1991, textes X et XI.

[2] M. Bullynck, Decimal periods and their tables: A German research topic (1765-1801), Historia Mathematica 36(2) (2009),137-160.

[3] M. Bullynck (Maarten) [2009] Reading Gauss in the computer age, Archives for the History of Exact Sciences 63(5) (2009), 553-580.

[4] M. Bullynck, A history of factor tables with notes on the birth of Number Theory 1657-1817, Revue d'histoire des mathématiques 16(2) (2010), 1-83.

[5] M. Bullynck and L. De Mol, Setting-up early computer programs: D. H. Lehmer's ENIAC computation, Archive for Mathematical Logic 49(2) (2010), 123-146. 
[6] J. W. L. Glaisher, Report of the Committee, consisting of Profs. Cayley, Stokes, Thomson, Smith and M. Glaisher on Mathematical Tables, Report of the Meeting of the British Association for the Advancement of Science 43 (1873/1874), 1-175, continued in: Rep. Brit. Ass. for Adv. of Sc., 1875/1876, 305-336.

[7] C. Goldstein, N. Schappacher, and J. Schwermer (eds.), The Shaping of Arithmetic: After C.F. Gauss's Disquisitiones Arithmetica, Berlin, Heidelberg: Springer, 2007.

[8] D. H. Lehmer, Guide to Tables in the Theory of Numbers, No. 105 in Bulletin of the National Research Council, Washington, D. C.: National Research Council, Committee on Mathematical Tables and Aids to Computation, Report 1: Report of the Subcommittee on Section F: Theory of Numbers, 1941.

[9] A. Schütz (Alfred) [1951] Choosing Among Projects of Action, Philosophy and Phenomenological Research 12, 161-184.

\section{Tabular texts of Babylonian mathematical astronomy MATHIEU OSSENDRIJVER}

Cuneiform tablets from the Late Babylonian period (450-50 BC) contain the first written evidence of mathematical astronomy in the ancient world, in the form of astronomical tables with computed data for the Moon and the planets, and procedure texts with the corresponding instructions. One puzzling aspect of the astronomical tables that has received little attention concerns the possible reasons why certain quantities are included in the tables while others are excluded. In order to shed light on this issue I briefly discuss the typology of the astronomical tables, after which I explore some aspects of the content of the tables.

Classification of the tabular texts. The corpus of tabular texts consists of approximately 340 tablets and fragments, which can be divided into four main groups:

(1) synodic tables (130 lunar, 100 planetary),

(2) template tables (38 lunar, 12 planetary),

(3) daily motion tables (10 lunar, 40 planetary),

(4) auxiliary tables (13 lunar, 7 planetary).

Synodic tables and daily motion tables constitute the end products of mathematical astronomy. The former contain computed data pertaining to the synodic phenomena (New Moons, Full Moons; for the planets e.g. first appearances, stations, and last appearances); contain daily positions. Template tables are essentially synodic tables lacking a column for the time and possibly other columns. Auxiliary tables contain auxiliary quantities such as reference values for interpolation schemes that are used for computing synodic tables. Hence they differ from template tables in that the quantities that are tabulated in them do not directly appear in synodic tables. Most daily motion tables contain daily positions of the Moon or a planet and the corresponding time or date. 
Synodic tables and template tables for the planets. The synodic tables for the planets contain the time $(T)$ and the zodiacal position $(B)$ for successive occurrences of one or more different synodic phenomena. They are computed in a line-by-line fashion by applying differences, such that $T_{i}=T_{i-1}+\tau$, and $B_{i}=B_{i-1}+\sigma$, where $\tau$ is known as the synodic time, and $\sigma$ as the synodic arc. Based on the algorithm by which $\sigma$ is computed, synodic tables can be divided into two main families, known as system A ( $\sigma$ is a step function of $B$ ) and system B ( $\sigma$ is a zigzag function). Most system-A tables contain only the 'final' quantities $T$ and $B$, while most system-B tables contain $\tau, T, \sigma$, and $B$, i.e. both final and auxiliary quantities. In addition to the synodic tables there are template tables, for both families of algorithms, containing only successive values of $B$.

The possible reasons why certain quantities are included in these tables while others are omitted are not really understood. The following observations may contribute to a better understanding of this issue. First, the presence of columns for $\tau$ and $\sigma$ in system-B tables implies that they, in spite of being the 'final products' of the algorithms or $T$ and $B$, incorporate data pertaining to intermediate steps of these algorithms. Hence the system-B tables can be viewed as representations of algorithms rather than only their end product. Secondly, there is nothing in the nature of the algorithms for $\sigma$ (and $\tau$ ) that would imply a necessity for including these quantities in a system-B table and omitting them from a system-A table. Perhaps the omission of $\sigma$ and $\tau$ from system-A tables is merely a convention for which there is no formal justification. Thirdly, although it is often assumed that the existence of template tables is explained by assuming that one can produce synodic tables for different dates from a single template table by copying its column $B$ and adding a column for $T$, this hypothesis is problematic. Usually there is very little choice (if at all) in assigning dates to the positions in the template tables, because the period after which the sequence of values for $B$ repeats itself tends to be very long (several centuries). It therefore seems more likely that a template table is simply the first stage in the production of a single synodic table.

Synodic tables and template tables for the Moon. While the typology of the planetary tables is still relatively easily described, the lunar tables, which can contain up to 18 different quantities, exhibit an even larger variation in terms of the selection of quantities that are included in the synodic tables and the template tables. In order to make sense of these tables it is again useful to distinguish between 'final' quantities and intermediate quantities. The former include, apart from the time and position of the lunation (New Moon or Full Moon), a function for eclipse 'magnitude' $(\Psi)$, and the so-called Lunar Six intervals, which are six intervals between the rising or setting of the Sun and that of the Moon around New Moon or Full Moon. All other quantities are intermediate in the sense that they reflect intermediate steps in the algorithms for computing the mentioned 'final' quantities.

Also for the lunar tables I want to make a number of observations. First, there are (virtually) no lunar tables that include all final quantities but no other quantities. Apart from a selection of final quantities the synodic tables always include 
a selection of intermediate quantities. This confirms what had been observed already for the planets, namely that the synodic tables are representations of the algorithms for the final quantities, rather than tables containing only final results of these algorithms. Second, while some intermediate quantities are regularly included, there are others that are always omitted; this is especially true for the algorithms for the Lunar Six intervals in system A, to a lesser extent in system B. Hence as representations of algorithms, the lunar tables are remarkably deficient with regard to the (highly complex) subalgorithms for the Lunar Six intervals. Also here the content of the tables may be guided by conventions that do not have any formal or practical justification. Third, since most synodic tables (especially those of system A) contain numerous intermediate quantities it is interesting that there are also template tables containing only a selection of intermediate quantities, but likewise associated with unique dates. As was remarked for the planetary tables, this suggests that lunar template tables are stages in the production of single synodic tables, rather than templates to be used for producing different synodic tables for different years. Some intermediate quantities were first written on template tables, after which a synodic table was compiled by combining data from the template tables, and adding columns for the final quantities.

\section{Mathematical tables in Ptolemy's Almagest NATHAN SidOLI}

In the Almagest, mathematical tables fit into Ptolemy's overall goals of presenting a mathematical structure of the cosmos, presented in an essentially single, structured argument. Indeed, Ptolemy makes a number of explicit assertions that the structure of the tables in the Almagest should agree with the overall project of mathematical astronomy and that they should exhibit both the true nature of the phenomena in question and have a suitable correspondence with the mathematical models [1, ex. vol. 1, 208 and 251]. Hence, in order to understand the role of tables in the Almagest, we must consider their function in the deductive framework of Ptolemy's mathematical presentation.

It is well known that Greek mathematical texts have quite specific forms that are so conspicuously marked that a knowledgeable reader would be able determine what part of a mathematical argument is being developed after reading just a sentence or two [2]. For example, in Euclid's Elements we encounter theorems and problems, and in the writings of Apollonius and Archimedes we find also analyses and calculations. Furthermore, many of these types of texts also have subdivisions that have been recognized and discussed by scholars at least as far back as Proclus [3]. In this context, we can understand tables as a kind of mathematical text in Ptolemy's argument.

One of Ptolemy's principle strategies, which he probably adopted from his predecessors, is to apply the types of mathematical texts found in the purely theoretical treatises, along with new kinds that seem to have arisen within the applied 
mathematical tradition, to the investigation of objects that he regarded as mathematical, such as harmonic intervals or heavenly bodies ([4], 93). We find the following types of mathematical text in Ptolemy's works:

Description: General application of a mathematical model to a physical situation.

Theorem: Straightforward mathematical proof (which must be interpreted by means of the model).

Problem: Demonstration that a certain construction is possible. (Rare, but ex. in Planisphere.)

Analysis: Argument by means of 'givens' that a certain calculation can be carried out. (Metrical resolution.)

Calculation: Use of the model to produce numerical values.

Table: List of numerical values based on the model and generally of use in further calculations.

Algorithm: General description of how we use the values in the table.

Of these, the last four are directly related to the construction and use of tables. Indeed, in the Almagest, tables are not found alone but are always in a group of related texts, which I call a 'table nexus.' The table nexus has a distinctive logical structure.

The tables in the Almagest are sets of numerical values that correspond to lengths and arcs in the geometric models from which they are derived. At least in principle, they are produced by direct derivation from geometric objects with assumed numeric values, or from a given geometric model with specific, astronomically determined, parameters. We can understand the tables themselves as a numerical representation of the underlying model, which is geometric. The tables are then used, either by Ptolemy or by his supposed reader, to provide an evaluation of specific values that relate both to the underlying model and to the heavenly bodies themselves.

In this way, we can outline the structure of the table nexus and relate its parts to the types of mathematical text that Ptolemy employs:

Derivation: A calculation or analysis that shows that given the model and its parameters, the numbers in the table are determined. (The table is, in fact, not always derived by the method Ptolemy provides ([5], [6]).)

Representation: A table, or series of tables, that gives a numerical representation of all of the key components of the geometric model. (Each moving part of the model has a separate entry.)

Evaluation: An algorithm that describes how the various entries in the tables can be used to calculate phenomena that we actually see.

Ptolemy himself does not explicitly address his methods and he gives no general statements of why he thinks they are valid or effective. Nevertheless, it is possible to construct an argument for the validity and purpose of the tables by considering the overall table nexus. For example, an understanding of how the components of the geometric model move can be derived from studying the table, the argument that the table represents a certain kind of function can be seen from the fact that 
the different columns refer to specific components of the model, an understanding of what each of the components of the table means can be based on an analysis of the figure, and arguments that the algorithms using the table actually produce apparent motion can be based on an assessment of how the terms of the table relate to the diagram.

We can take the solar theory, set out in book III of the Almagest as a general example of how the table nexus should function. We will consider the table nexus for the table of solar anomaly, Alm. III 6, which is composed of Alm. III 5, 6 and 8.

Alm. III 5 gives a calculation for the equation of anomaly $(\alpha)$, given the parameters of the model and a mean normed longitude $(\bar{\kappa})$ of $30^{\circ}$. Analyses are then used to show that given any other values for one of $\bar{\kappa}, \kappa$ or $\alpha$, the other two are also given. This can be taken as a demonstration that the numeric values corresponding to these angles in the model are all determined.

This is then followed by the table of solar anomaly, Alm. III 6, which sets out corresponding values of $\bar{\kappa}$ and $\alpha$. Each of the entries in this table are direct representations of an angle in a possible diagram of the model. Hence, the nature of the function depicted by the table can be understood as predicated on the basis of an intuitive understanding of the geometric properties of the model.

After the values of $\bar{\kappa}, \kappa$ and $\alpha$ at epoch are established in Alm. III 7, the final section of the table nexus, Alm. III 8, gives an algorithm for using the values in the table of solar anomaly, along with the table of mean solar motion, Alm. III 2, to compute the apparent position of the sun for any time since epoch. There is no attempt to justify the operations of the algorithm; however, since all of the values in the computation are direct representations of objects in the model, which in turn directly represent the celestial bodies, we may take everything that has lead up to the the algorithm as its justification.

As usual in the Almagest, we can read the solar theory as a sort of model; however, because of its simplicity, none of the other theories can be patterned on it exactly. In the solar theory, each of the entries in the table can be related to a specific object in the model. Hence, one could argue that the justification for the algorithm, Alm. III 8, can be read off the model itself.

In the more involved theories, where Ptolemy tabulates functions of more than one variable (Alm. V 8 and XI 11), individual entries in the tables will correspond to multiple positions of the model, and interpolation will be used for the intervening positions. Nevertheless, the justification for the final algorithm can still be made by referring to the geometric features of the model, although Ptolemy does not, himself, do this. Perhaps he thought the derivation was sufficient.

\section{REFERENCES}

[1] J. L. Heiberg, Claudii Ptolemaei, Syntaxis mathematica, Leipzig: Teubner, 1898-1903.

[2] R. Netz, The Shaping of Deduction in Greek Mathematics, Cambridge: CUP, 1999.

[3] R. Netz, Proclus' division of the mathematical proposition into parts: How and why was it formulated?, Classical Quaterly 49 (1999), 282-303.

[4] I. Düring (ed.), Die Harmonielehre des Klaudios Ptolemaios, Göteborg: Göteborgs Högskolas Årsskrift, 1930. Reprinted Hildesheim: Olms, 1982. 
[5] R. R. Newton, The Origins of Ptolemy's Astronomical Tables, Baltimore: Johns Hopkins University, 1985.

[6] G. Van Brummelen, Mathematical Tables in Ptolemy's Almagest, Ph.D. Thesis, Simon Fraser University, Department of Mathematics and Statistics, 1993.

\section{Astronomical tables in second millennium Sanskrit sources}

\section{Clemency Montelle}

One important strand in the study of numerical tables in Sanskrit sources comprises of the so-called koșthakas or sārañis, astronomical tables that rose in popularity from the tenth century onwards. It has been argued that the prominence of these types of tables in Sanskrit astronomy was linked to Islamic inspiration particularly through the influence of the $z \bar{\imath} j$ compositions ([1], 41; [4]). Unlike the standard Sanskrit astronomical formats that contained enumerations of important parameters and fundamental algorithms composed in verse, these works used spatial arrangement, ruled rows and columns, alignment, and accompanying explanatory prose to present precomputed data intended for practical astronomical application.

The earliest text of this type that we know of is a work authored by the Indian astronomer Durlabha who was working at Multān in Sind. We know of this work not directly, but through descriptions of it that are given by al-Bīrūnī in his work India. The epoch of Durlabha's tables are given as Śaka 854 (=932 CE) and in subsequent centuries dozens of tables were produced in India. The tables that have been catalogued so far by modern efforts come predominantly from North Western India, with a handful from Kāśí and Bengal. This geographical concentration further evidences the impact that Islamic sources had on the Indian tradition. Tables do exist from other regions of India, however, their content reveals them to be largely independent of Islamic inspiration. This is particularly pertinent to the tables found in South India.

In addition to new works, many authors found their inspiration in key astronomical texts from previous times. Extracting the base parameters which had been expressed in prose, they cast and developed the relevant astronomical data in a tabular format. For example, Bhāskara II's (b. 1114) work, the Karanakutūhala was recast as tables by Nāgadatta and called the Brahmatulyasāraṇi the Karanakutūhalasāraṇ̂ $)$ with an epoch of 23 February 1183. Other similar instances abound: a tabular version of Brahmagupta's Khandakhädyaka, enti-

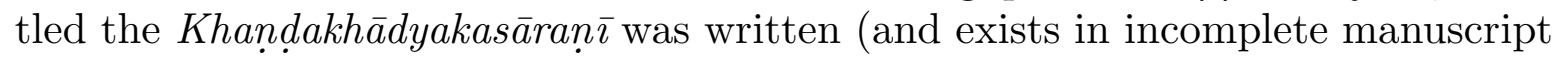
form), the Süryasiddhāntasārin̄ī based on the Sūryasiddhānta was prepared, and the Grahaläghavasāraṇ̄ was composed by Nīlakaṇtha in 1630 based on Ganeśa's Grahalāghava (1520), as well as another work by the same name by Porema in 1656 .

To rationalise the corpus, astronomical tables have been classified into several distinct types [2]). These include Planetary tables, Pañcāngas or Calendrical tables, Eclipse tables, and Geographical tables. The parameters of the tables can generally be further classified, both with respect to their base parameters and their 
mathematical structure. As with conventional astronomical texts, the parameters of tables fall into the five broad paksas or schools prevalent in Indian mathematical astronomy. These are the Āryapakșa, the Ārdharātrikapakșa, the Brāhmapakșa, the Saurapakșa, and the Ganeśapakșa. In addition, planetary tables generally follow one of the following three mathematical structures: mean linear, true linear, or cyclic.

Mean linear tables arrange their data, the mean longitudes of the planets, with respect to time, tabulating by means of increasingly smaller time increments. Anomalies are tabulated separately and to be applied to the mean longitudes to find the true positions. This format forms the basis of the Ptolemaic tables. By contrast, true linear tables tabulate the true longitudes of the planets. These tables are arranged according to an ideal year in which the initial position of the sun is set at Aries $0^{\circ}$ and data is tabulated according to 2 -week periods. This format seems to be an Indian innovation. Lastly cyclic tables, as their name implies, tabulate planetary longitudes over individual cycles, an appropriate period of years for each planet in which the true longitudes are given for each 2-week period within this cycle. These tables appear late in the corpus in around the seventeenth century and appear to be based on Babylonian Goal-Year periods that were introduced into the Indian astronomical tradition via Islamic sources.

Another important type of tabular texts are Pañcāngas, tables for computing important elements in the calendar. Meaning "having five-limbs", these tables give the occurences and details of the five major subdivisions of the Indian calendar: vāras, tithis, nakșatras, yogas, and karanas. These were intended to assist astrologers in computing the details of the calendar, the correct times for festivals and special days, and other events. Tables designed specifically for computing the details and circumstances of eclipses are often made, sometimes as part of larger collections of tables, and sometimes as independent works. The Karanakesari of Bhāskara (fl. 1681) is a set of astronomical tables for computing lunar and solar eclipses. Their epoch is Śaka 1603 (1681 CE) and the tables contain elongations, apparent lunar and solar diameters, measures of the shadow cone, half-durations, 'deflection', and parallax, as well as other relevant astronomical parameters. There exists a short accompanying text to supplement these tables which comprises of 20 verses as supplementary explanation.

More broadly, the contrasting intellectual circumstances in India have had a marked effect on the practice and tradition of science, particularly with respect to tables. An examination of these tables and an investigation into the resulting underlying mathematical techniques, interpolation conventions, and iterative procedures that were developed in response to the needs of the table-makers over the many centuries in which the genre flourished can reveal key trends in the approaches and attitudes of these scholars. Tables therefore provide direct and valuable evidence for the mathematical historian as to how Indian practitioners advanced and justified developments in the astronomical field. 


\section{REFERENCES}

[1] D. E. Pingree, Jyotihśáastra, Wiesbaden: Otto Harrassowitz, 1981.

[2] D. E. Pingree, On the classification of Indian planetary tables, Journal for the History of Astronomy 1(2) (1970), 95-108.

[3] D. E. Pingree, Sanskrit astronomical tables in the United States, Transactions of the American Philosophical Society (New Series) 58(3) (1968), 1-77.

[4] K. Plofker, Mathematics in India, Princeton, NJ: Princeton University Press, 2008.

\section{Vākyas: Astronomical tables in sentences MaHESh KoOLAKKODLu}

Vākya and katapayādi notation of numerals. The Sanskrit word Vākya literally means a sentence. A vākya may consist of either a single word or a group of words. A text named Vākyakarana (ca. $1300 \mathrm{CE}$ ) presents tabulated numerals in the form of vākyas ${ }^{1}$. The vākyas are constructed using katapayādi method, a verbal system of denoting numbers. In this system, each letter of Sanskrit represents a digit. To denote a number, letters are grouped to construct a meaningful word or phrase. The alphabets along with the value they represent are displayed below:

\section{Vowels}

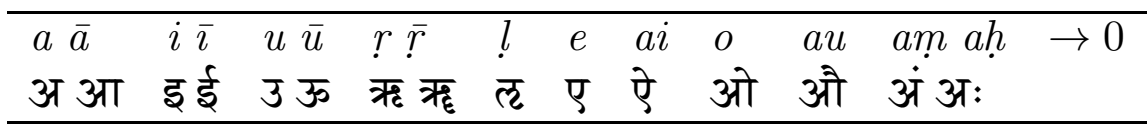

\section{Consonants}

\begin{tabular}{llllllllll}
\hline 1 & 2 & 3 & 4 & 5 & 6 & 7 & 8 & 9 & 0 \\
\hline$k a$ & $k h a$ & $g a$ & $g h a$ & $\dot{n} a$ & $c a$ & $c h a$ & $j a$ & $j h a$ & $\tilde{n} a$ \\
क & ख & ग & घ & ङ & च & छ & ज & झ & न \\
$t a$ & $t h a$ & $d a$ & $d h a$ & $n a$ & $t a$ & $t h a$ & $d a$ & $d h a$ & $n a$ \\
ट & ठ & ड & ढ & ण & त & थ & द & ध & न \\
$p a$ & $p h a$ & $b a$ & $b h a$ & $m a$ & & & & & \\
प & फ & ब & म & म & & & & & \\
$y a$ & $r a$ & $l a$ & $v a$ & $s a$ & $s a$ & $s a$ & $h a$ & $d a$ & \\
य & र & ल & व & श & ष & स & ह & के & \\
\hline
\end{tabular}

A consonant without vowel represents nothing. (e.g. $k, j$ ). A vowel attached to a consonant has no value (e.g. $e$ in $k e, \bar{\imath}$ in $j \vec{\imath}$. In the case of a conjunct letter the consonant at the end connotes the value (e.g. $d y \bar{a}=y \bar{a}: 1)$. The letters are chosen such that the string could give a beautiful meaning so that a mnemonic string is constructed. The number has to be read from right to left (e.g. jarmani=850 $\rightarrow$ 058). This type of numerical notation is mostly used in south India. In the following section, let us see one such instance from Vākyakarana.

\footnotetext{
${ }^{1}$ This text has a commentary by Sundararāja (ca. 1500 CE).
} 
Transit vākyas. The entry of the Sun into a sign from another is called transit or sankrama. This marks the beginning of a solar month. Vākyakarana provides transit vākyas in order to compute the day and the time of the transits of the Sun into different signs.

\section{श्रीर्गुणमित्रा भूर्विधिपक्षा स्त्रीरतिशूरा मोगवराते ॥१ ॥ \\ भावचरोरिः तेनवशत्वम् लोकजभीतिः स्थूलहयोऽयम् ॥श॥ \\ अङुधिगारः स्तम्भितनाभिः नित्यशशीशों यागमयोऽयम् ॥३॥ \\ तावुरुपूर्वं सङ्रमवाक्यं तत्क्रमयोज्यं पादवशेन ॥४ ॥}

These four verses are in a meter called parikti. Every quarter of each verse contains five letters. The metrical constraint here is that the second and third letters should be short having non-conjunct letter next to them. Others should be either long or short preceding a conjunct letter. The first three verses present the transit vāyas. In total, twelve numerals are listed (four in each verse) using katapyādi notation. Each quarter of the verse presents five digits. These digits spell the time and weekday of transit. The first digit indicates the weekday elapsed before transit. The succeeding four digits tell the time of transit in ghatīs and vighatīs. The information we get from the above verses can be displayed as follows (the transliterated form of the verses is given):

\begin{tabular}{|c|c|c|c|}
\hline Sign & $\overline{V \bar{a} k y a}$ & Number & Meaning \\
\hline 2 & śrīrgunamitrā & $2^{d} 55^{g} 32^{v}$ & Prosperity is associated with virtues \\
\hline 3 & bhūrvidhipakșā & $6^{d} 19^{g} 44^{v}$ & The land supported by law \\
\hline 4 & strīratiśūrā & $2^{d} 56^{g} 22^{v}$ & A woman who is a good enjoyer \\
\hline 5 & bhogavarāte & $6^{d} 24^{g} 34^{v}$ & This is a better enjoyment for you. \\
\hline 6 & bhāvacarorih & $2^{d} 26^{g} 44^{v}$ & The [actual] enemy resides in sentiment \\
\hline 7 & tena vaśatvam & $4^{d} 54^{g} 06^{v}$ & getting controlled by that \\
\hline 8 & lokajabhītih & $6^{d} 48^{g} 13^{v}$ & dread arisen in the world \\
\hline 9 & sthūlahayo'yam & $1^{d} 18^{g} 37^{v}$ & This is a dull horse \\
\hline 10 & à̇gadhigārah & $2^{d} 39^{g} 30^{v}$ & One who has crooked parts (?) \\
\hline 11 & stambhitanābhih & $4^{d} 06^{g} 46^{v}$ & Fixed centre \\
\hline 12 & nityaśaśisó & $5^{d} 55^{g} 10^{v}$ & Moon-god who is eternal (?) \\
\hline 01 & yāgamayo'yam & $1^{d} 15^{g} 31^{v}$ & This is full of sacrifice \\
\hline
\end{tabular}

The numbers given here are obtained through the relation $V_{i}=\bmod \left[D_{i}, 7\right]$ (where $D_{i}$ is the exact number of days taken by the Sun to cover $i 30^{\circ}$ of the ecliptic; $i=1$ to 12). Fraction of a day is converted into ghatīs and vighat $\bar{s}^{2}$. The fourth verse prescribes the method of employing the given numerals in the computation of transit. It says that the vāky $\bar{a} s$ correspond to the signs starting from Taurus, the second sign. In other words, it can be understood that $n^{\text {th }} v \bar{a} k y a$ stands for the transit of the Sun into $(n+1)^{t h}$ sign. [The numerals represented by] the vākyas should be added to the day and time of the first transit.

tāvurupūrvam sarikramavākyam tatkramayojyam pādavaśena $\|4\|$

The transit vākya should be added in order starting with Taurus according to [the rank of its] quarter.

\footnotetext{
${ }^{2} 1$ day $=60$ ghațiss 1 ghaț $=60$ vighaț $\bar{s}$.
} 
The procedure for computing the first transit is stated in the Vākyakarana before presenting the vākyas.

\section{REFERENCES}

[1] T. S. Kuppana Sastry and K. V. Sarma (eds. and transl.), Vākyakarana with the commentary Laghuprakāśikā, Mylapore: Kuppuswami Sastri Research Institute, 1962.

[2] K. Candrahari, Vākyakaraṇa - A study, Indian Journal of History of Science 36(3-4) (2001), $127-149$.

\section{On the development of navigation tables in early modern England} THOMAS SONAR

The earliest means of celestial navigation were the observation of the pole star (polaris) at night and the observation of the sun at noon. Both methods give the latitude of the observer; longitude could not be determined until clockmaker John Harrison devised a watch which was exact on sea over months and in any weather in the 18th century. The determination of latitude from observation of the pole star is simple in theory and I have not described the procedure in this talk.

The determination of latitude by observation of the sun at noon is much more complicated since the sun moves through the ecliptic.

It is advisable to compute from astronomical data 4 declination tables of the sun starting at a leap year. If the 4 years' cycle is over the first table can be used again without much loss of accuracy. This procedure, however, was not followed before the tables of William Bourne in 1571.

The earliest navigation manual we know of is a work printed in 1509 in portuguese as Regimento do Astrolabio e do Quadrante, written by the physician, mathematician, mariner, and astronomer José Vizinho. Vizinho was a Portugueseborn Jew who studied with the famous sephardic astronomer Abraão Zacuto. Vizinho traveled several times down the west coast of Africa as far as to the equator. In 1485 he was send to the coasts of Guinea by the king João II. to develop nautical methods for the purpose of sailing. With Martin Behaim he constructed and built an astrolabe made from wood. Vizinho was befriended with Columbus. The astronomical data (ephemerides) necessary for the tables in Vizinho's manual came from the famous Alfonsine tables, compiled in the 13th century on the order of Alfonso the Wise of Castilia.

When the Regimento was published in 1509 the situation of the English with respect to navigational skills was still staggering. English sailors in the channel used so-called rutters, small pocket books conatining details of the French and English coasts, compass directions, and distances between ports and capes which were derived in France around 1480 by one Pierre Garcie. This rutter was translated into English as early as 1528 and was restricted to Channel and the Biscaya. In 1541 one Richard Proud published an English The rutter of the sea, still based on Pierre Garcie's book but enriched with 15th century data of English waters. Would the Regimento have been available to English mariners early in the 16th century it would have been completely useless since mathematics beyond simple 
mercantile techniques was unknown. It was not before the middle of the 16th century after the two teachers of the English people in mathematics - Robert Recorde and John Dee - had layed the mathematical foundations, that advanced navigational techniques became intelligible in England.

In 1542 French hydrographer Jean Rotz went from Dieppe to offer his services to King Henry VIII. He took with him his invention of a variation compass and a work on the shortcomings of present-day navigational techniques. He became Hydrographer to the King, published the Book of Hydrography and certainly had considerable influence on the development of navigation in England - however, to my knowledge his exact role is still not clear. When King Henry died in 1547 it is said that sixty French pilots were enrolled in the service of the English court.

The Regimento do Astrolabio e do Quadrante was the blueprint for subsequent Spanish works, namely the Arte de navigar of Martin Cortés which was published in Spain in 1551 and became known also under the title Breve compendium. As early as 1561, only ten years after its original publication in Spain, Richard Eden published an English translation of Arte de navigar, The Arte of navigation.

The look-up of the declination necessitated the use of no less than three different tables. The first one is called "The table of the true place Of the Sunne". This table was computed for a specific year only so that only day and month can be used for the lookup. The second table corrects for the particular year one is in. Now one has find the true position of the sun. From the third table this true position then gives us the declination.

A table-lookup procedure with three different tables was much too complicated for the ordinary English seamen and this became clear quite early on. A dramatic breakthrough was achieved by an inn-keeper, gunner, and mathematician from the port of Gravesend, William Bourne (ca. 1535-1582).

He learned his mathematics from the books by Recorde and showed much interest in practical navigation. After having intensly studied Cortés' Arte of Navigation he published in 1567 his Almanacke and Prognostication from which no copy has survived. However, there is a second edition published 1571 in which Bourne reprinted the same declination tables as in his first edition. Only one table is necessary in contrast to three in Cortés' book.

Looking up the 22nd of February 1568, Bournes table gives us a declination of $6^{\circ} 52^{\prime}$ which makes a difference of $19^{\prime} \approx 34$ sea miles with Cortés' value. Bournes "Almanacke" is the first book including declination tables for a 4 years period.

In 1574 Bourne published A Regiment for the Sea: Conteyning most profitable Rules, Mathematical experiences, and perfect knowledge of Nauigation, for all Coastes and Countreys: most needefull and necessarie for all Seafaring men and Trauellers, as Pilotes, Mariners, Marchants, $6 c$. which became the definite navigational book of the next decades.

As early as 1594 declination tables of the sun were so common that their use was described even in popular books for the education of young gentlemen. 
In Thomas Blundeville's (ca. 1522-ca. 1606) His Exercises, containing sixe Treatises... we find a simple declination table for educational purposes. The declination can be read off if the sign of the zodiac is known in which the sun stands.

The next step forward was achieved by the still somewhat mysterious Thomas Harriot (1560-1621), the greatest English mathematician of his times. Working for Sir Walter Raleigh he certainly was aware of the needs of the mariners in all problems navigational. Being an able astronomer himself he mistrusted old ephemerides and started his own measuring campaign. He measured the inclination angle of the ecliptic where he even took the parallax as well as the refraction in the atmosphere into account. In his table Regiment of the sun, compiled from 1593-1596 he introduced a difference column in red ink for purposes of redundancy. These tables were thoroughly examined and re-computed with the help of modern computers by Roche in a beautiful paper in the British Journal for the History of Science in 1981. Tables like Harriot's were never seen before as far as exactness is concerned. But Harriot was hysterically scary to publish anything in his lifetime and his tables most likely experienced not the circulation they deserved.

The last step in the development of English declination tables was therefore not obtained by Harriot, but by Edward Wright (1561-1615), cartographer, mariner, and perhaps the greatest living applied mathematician in his days.

He is well know for his rigorous construction of the Mercator map and for his book Certain Errors in Navigation, Arising either of the ordinarie erroneous making or vsing of the sea Chart, Compasse, Crosse staffe, and Tables of declination of the Sunne, and fixed Starres detected and corrected which was published in 1599 and saw many new editions in the 17th century.

Wright's declination tables include many of the advances which Harriot brought into table making: exactness and the difference column for redundancy. The table was computed by Wright's close friend Henry Briggs as we are informed in the foreword of the second edition. Since his table is very close to Harriot's one may wonder about a hitherto unknown connection between Harriot, Briggs, and Wright. Wright is also the first to note that declination tables are valid only for the latitude of the place where they were computed, say London, and that the mariner on sea had to correct for his position.

Wright's book marks the grand finale in the development of navigational techniques by the English. In only 38 years between the publication of the English translation of Cortés' Arte of Navigation in 1561 and Wright's first edition in 1599 the English managed to lay the foundation for the Nautical Almanac which was first published in the 18th century.

\section{REFERENCES}

[1] M. Cortès, Arte of Navigation (1561), Scholar's Facsimiles \& Reprints, 1992.

[2] Th. Sonar, The 'Regiments' of sun and pole star: on declination tables in early modern England, GEM - International Journal on Geomathematics 1 (2010), 5-21.

[3] E. G. R. Tylor, A Regiment for the Sea, Cambridge: University Press, 1963. 


\section{Range tables at the beginning of the twentieth century DAVID AuBin}

In this talk, I explored the production and use of ballistic tables in the first decades of the 20th century. Based on the French case which I study in more detail in [1] (see also [2]), my argument focused on three categories of actors involved in the process, namely artillerymen, ballisticians properly speaking and scientists, mathematicians for the most part. I showed that the challenges posed by the technological innovations of the last decades of the 19th century were adequately met by professional ballisticians who worked in rather standard disciplinary environment. World War I introduced new use of artillery and required to overhaul computing methods for ballistic tables.

The ballistic problem has been known for a long time. In its simplest form, it involved solving a differential equation of the form ([3], 449):

$$
d v_{x}=\frac{c v}{g} F(v) d \tau
$$

where $v$ is the magnitude, and $v_{x}=v \cos \tau$ the horizontal component, of the velocity $v$ of the projectile in the $(x, y)$-plane, expressed as a function of the uniformly decreasing angle $\tau$ with respect to the horizontal at each point of the trajectory; $g$ is the acceleration due to gravity at the surface of the earth (taken in first approximation to be constant); $c$ the so-called "ballistic coefficient" (varying according to the size and shape of the projectile); and $F(v)=f(v) / v^{2}$ the law of resistance of the air to the motion of the projectile supposed in first-order approximation to be a function of $v$ only.

Easily integrable for air drag law where $f(v)$ is a power of $v$, the equation has to be approximated when a more complicated function is chosen. In the nineteenth century, several technological advances had forced ballisticians to abandon all hopes of being able to use such a simple function to approximate air drag over a range of velocities up to, and higher than, $1000-1200 \mathrm{~m} / \mathrm{s}$. The combination of breach-loading systems, riffled guns made of iron, pointed-nose projectiles, and smokeless powder had indeed significantly increased initial projectile velocities. The air drag function was established experimentally and a functional representation was given (but of course never used) ([4], 16):

$$
F(v)=0.2002 v-48.05+\sqrt{(0.1648 v-47.95)^{2}+9.6}+\frac{0.442 v(v-300)}{371+\left(\frac{v}{200}\right)^{10}} .
$$

As a result, while the relevance of ballistics had somewhat increased for fighting artillerymen, computing methods needed to be revised. In the last decades of the 19th century, the field of external ballistics shared many of the standard attributes one associates with scientific disciplines. There was a principal problem one could solve in several ways and a host of secondary problems addressed by using adequate approximation methods. There was an international community of ballisticians in which experimental results and theoretical considerations circulated almost freely in standard treatises and specialized journals. Scientific leaders had emerged in 
most European countries: Francesco Siacci in Italy, Alfred Greenhill in England, Carl Cranz in Germany, and Proper-Jules Charbonnier in France. All of them were working in military institutions whose main purpose was ballistics.

There were two standard methods for computing range tables from theory. At the Gâvre Commission (the main experimental station for ballistics in the French Navy, see [5]), the step-by-step integration method developed by Euler was used by Hubert Gossot and his team. This methods was computation-intensive but very reliable. In 1906, when Charbonnier became president of the Gâvre Commission he decided to adapt Siacci's method instead. This method allowed one to compute directly the elements of a trajectory using the tabulated values of some auxiliary functions:

$$
\begin{array}{ll}
J(u)=-g \int \frac{d u}{u F(u)} & D(u)=-\int \frac{u d u}{F(u)} \\
S(u)=-\int \frac{d u}{F(u)} & A(u)=-\int \frac{u J(u) d u}{F(u)} .
\end{array}
$$

This computational effort was completed in $1915 \ldots$ at which time it was superseded by a return to Eulerian methods. Changing fighting conditions were mainly responsible for this return to step-by-step integration methods. With the development of indirect fire, heavy artillery and high-angle shooting in anti-aircraft gunnery, the small-angle approximation used by Siacci and Charbonnier could not be used anymore.

To carry out the large amount of computations needed to compute new tables, mathematicians were drafted at Gâvre. Although ballisticians were well accustomed to integration methods, mathematicians provided them with important results concerning the evaluation of errors, probabilistic deviation and methods for computing "differentials" (that is, corrections to be used in specific shooting conditions to account for wind, temperature of the atmosphere, wear of the piece, etc.).

At the end of 1917, according to General Herr, "the time ha[d] come when the French artillery at long last found, if not a complete and definitive [answer], at least one that was precise enough to be applicable so forth." The solution to the problem of firing by surprise was "the scientific preparation of shooting [la préparation scientifique du tir]" ([6], 93). Although less praised than tanks and less bedeviled than poison gas, the new firing methods played no small part in the outcome of the war. "It was the massive surprise action of our artillery which, from 18 July, 1918 onwards, insured the success of our great offensives until Germany's capitulation" ([7], 122). Ballisticians, it would seemed, had successfully fulfilled their mission. I have argued that this success owed much to their ability to enroll the effective collaboration of some mathematicians.

\section{REFERENCES}

[1] D. Aubin, 'I'm just a mathematician': Why and how mathematicians collaborated with military ballisticians at Gâvre, in: The War of Guns and Mathematics: Mathematical Practices and Communities in Allied Countries around World War I, D. Aubin and C. Goldstein (eds.), forthcoming. 
[2] D. Aubin, The war of guns and mathematics: French mathematicians, ballisticians and artillerymen in World War I (The case of Jules Haag at Gâvre), Oberwolfach Reports 5 (2008), 1350-1352.

[3] P.-J. Charbonnier, Historique de la balistique extérieure à la commission de Gâvre, Revue maritime et coloniale 168 (1906), 411-476.

[4] C. Cranz and E. Vallier, Balistique extérieure, in: Encyclopédie des sciences mathématiques pures et appliquées, J. Molk and P. Appell (eds.), tome IV, $6^{\mathrm{e}}$ volume, $1^{\mathrm{er}}$ fascicule, Paris: Gauthier-Villars and Leipzig: Teubner, 1913.

[5] L. Patard, Historique de la Commission d'expériences de Gâvre (1829-1930), suppl. au Mémorial de l'artillerie française, Paris: Imprimerie nationale, 1930.

[6] F.-G. Herr, L'Artillerie, ce qu'elle a été, ce qu'elle est, ce qu'elle doit être, Paris: BergerLevrault, 1923.

[7] J. Campana, Les Progrès de l'artillerie: l'artillerie française pendant la guerre de 19141918, Paris: Lavauzelle, 1923.

\section{Numerical and graphical tables developed in interaction between university and industry in the first half of the 20th century Renate Tobies}

The range of research questions of this field were presented in a survey lecture. On this basis, we discussed (also in additional two sessions) the new developed table concept created around 1900:

(1) The solution of an equation by tabular calculation ([1], 2nd ed., 41-44).

(2) Nomograms as tables (especially [2] and [3]; see also [4]).

Numerical and graphical tables became generic components of different disciplines for solving problems in the initial period of modern Numerical Analysis, and when applying Mathematical Statistics on mass production. If we compare the function of tables with modern computer, they were forerunner instruments. Tables were developed and used for solving equations and systems of equations, for integration of differential equations, etc. The following questions were discussed:

- What kinds of tables were developed?

- How can we classify the large number of different tables?

- Who developed tables? Or: What kinds of interaction between university and industrial research developing tables can we identify in Germany and other countries?

- For which purpose numerical and graphical tables were designed?

- Do we have another kind of table concept generalized by Carl Runge - the first professor of applied mathematics at a German University?

- What kinds of international and national correlation designing tables existed between different research communities?

To answer these questions, a detailed study of new sources was proposed. In recognition of the fact that the new table concept was created by the founder of modern numerical analysis Carl Runge (how Lothar Collatz referred to him in 1990), it should be analyzed: 
1) The table papers and their authors published in the Zeitschrift für Mathematik und Physik [Journal for Mathematics and Physics] since 1901, when Carl Runge became one of its main editors and the journal devoted its pages exclusively to the promotion of applied mathematics. In 1901, Runge and Mehmke include to write in their editorial: "Moreover, we would like to devote considerable attention to the technical instruments that are used by the practitioners of these fields, including numerical and graphical tables, mechanical calculators, and graphical instruments."

2) The use and development of the table concept by Carl Runge, his doctoral and postdoctoral students also from abroad in interaction between engineering knowledge and interdisciplinary research seminars of applied mathematics regularly hold at the University of Göttingen by professors of mathematics, applied mathematics, applied mechanics, geophysics, and theoretical physics. (Source: Felix Klein's minutes of Seminars [Seminarprotokolle] which he headed together with colleagues.)

3) New tables (Rechentafeln) published in the Zeitschrift für angewandte Mathematik und Mechanik [Journal for Applied Mathematics and Mechanics] - which appeared in the publishing house of the Association of German Engineers - founded by Richard von Mises, the use of these tables and their input in books which tried to systemize all results. In the editorial of his journal, Richard von Mises had offered the following prognostication: "Far more comprehensive and ripe for further development are undoubtedly the methods of graphical calculation, which is capable of accomplishing everything that numerical calculation is able to accomplish."

4) Laboratory Reports, Papers, and books written by industrial researchers of German electrical engineering corporations including new developed results on graphical and numerical tables were analysed in our recent research project [5] and presented in the lecture within the international context. Here, it should be only mention two representative books: Richard Becker, Hubert C. Plaut, and Iris Runge, Anwendung der mathematischen Statistik auf Probleme der Massenfabrikation [The Application of Mathematical Statistics to Problems of Mass Production] [6] - the first book of its kind in any language -, written under the aegis of Osram's main research department, and its included table concept (numerical tables for calculation the variance [statistisches Fehlerquadrat], the uniformity factor [logarithmisches Streuungsmaß], tables for Gaussian (normal) distribution curves, the Gaussian Error Integral, and different graphical tables); Marcello Pirani, Graphische Darstellung in Wissenschaft und Technik [Graphical Representation in Science and Engineering] [7]. The purpose of this book, in contrast to Carl Runge's textbook on Graphical Methods [3], was to provide industrial engineers and physicists with a resource for creating, on their own, graphical tables that could be employed in solving concrete, practical problems. Both books embraced results, tables, which were internationally obtained. One of the main objectives is to get to know the implementation of the new table concept in interaction of industrial research in internationally interwoven corporations (Osram, Telefunken, General Electric Company, RCA, etc.). 


\section{REFERENCES}

[1] C. Runge, Praxis der Gleichungen, Leipzig: Göschen, 1900; 2nd ed., Berlin: de Gruyter, 1921.

[2] M. d'Ocagne, Traité de nomographie, Paris: Gauthier-Villars, 1899; 2nd ed., 1921.

[3] C. Runge, Graphical Methods, New York: Columbia University Press, 1912. German translation: Graphische Methoden, Leipzig: Teubner, 1915; 2nd ed., 1919; 3rd ed., 1928.

[4] D. Tournès (ed.), Histoire du calcul graphique, Paris: Cassini, forthcoming.

[5] R. Tobies, Morgen möchte ich wieder 100 herrliche Sachen ausrechnen. Iris Runge bei Osram und Telefunken, Stuttgart: Steiner, 2010. English translation: Iris Runge and The Bridges Between Mathematics, Industry, and Culture, Basel: Birkhäuser, 2012.

[6] R. Becker, H. C. Plaut, and I. Runge, Anwendungen der mathematischen Statistik auf Probleme der Massenfabrikation, Berlin: Springer, 1927; 2nd ed., 1930.

[7] M. Pirani, Graphische Darstellung in Wissenschaft und Technik, Leipzig: Göschen, 1914; reprinted in 1919 and 1922; second revised and extended edition by Iris Runge in 1931.

\section{Numerical sampling tables in industry: Design and practice DENIS BAYART}

Since the 1920s numerical sampling tables have been used in industry to specify procedures of quality control by random sampling, called "acceptance sampling plans" [1]. Given a "lot" of products, a sample is drawn at random; the lot is accepted or rejected according to the number of defects observed in the sample.

The simplest probability model consists in an urn containing $\mathrm{N}$ good and bad chips, in unknown proportion. The probability that the rate of bad chips in the urn be greater than a predetermined number can be computed using Poisson, binomial or multinomial laws.

Tables usually give the sample size and "acceptance number" (number of defects in the sample beyond which the whole lot must be rejected) corresponding to a set of parameters: lot size, "client's risk" (probability that a bad lot may be accepted as a good one), "producer's risk" (probability that a good lot may be rejected). The concepts of risk are similar to the two kinds of error in Neyman-Pearson's theory but they have emerged independently [2].

The curve showing the probability of acceptance as a function of the rate of defects in the lot, given sample size and acceptance number, is called "operational characteristic curve". It provides a good view of the global properties of a sampling plan. A sampling plan can thus be represented in three semiotic modes complementing each other: numerical calculations, geometrical curve, symbolic equation.

A rich corpus of historical material allows us to study the practice which developed about sampling plans. Study of practice is necessary to understand the genesis of sampling tables in industry. Tables have been designed to fit some specific classes of situations. It is the variety of situations which explains the variety of tables which have been published and used. The material presentation of tables, for example, will make them more or less easy to use by ordinary workers in industry. To study the relation of tables to action, concepts borrowed from the field of pragmatics may be useful [3]. Focusing on action rather than on knowledge 
may be important in industrial contexts. For example, the purpose of a sampling plan is to act upon the lot (i.e. to accept, to screen or to reject it) rather than to represent a set of quality data.

Sampling plans have also been designed as norms to legally define the conditions of industrial and commercial exchanges. Normalization committees and agencies were involved early in USA, UK, France. The status of a norm appears as a very strong factor of diffusion of the tables. At the same time it implies codification and rigidity.

\section{REFERENCES}

[1] A. Hald, Statistical Theory of Sampling Inspection by Attributes, London: Academic Press, 1981.

[2] H. F. Dodge and H. G. Romig, A method of sampling inspection, Bell System Technical Journal 8 (1929), 613-631.

[3] C. W. Morris, Foundations of the Theory of Signs, Chicago: University of Chicago Press, 1938. 


\section{Participants}

Prof. Dr. David Aubin

Institut de Mathematiques de Jussieu Histoire des Sciences Mathematiques Case Postale 247

4, place Jussieu

F-75252 Paris Cedex 05

\section{Dr. Denis Bayart}

Centre de Recherche en Gestion

Ecole Polytechnique et CNRS (UMR 7176)

ENSTA-PREG-CRG

32 Boulevard Victor

F-75739 Paris Cedex 15

Prof. Dr. Glen van Brummelen

Quest University Canada 3200 University Boulevard Squamish, BC V8B 0N8 CANADA

\section{Prof. Dr. Maarten Bullynck}

184 bis, Rue du General de Gaulle F-59110 La Madeleine

Prof. Dr. Karine Chemla Universite Paris 7 - CNRS

Laboratoire SPHERE UMR 7219

Equipe Rehseis, Case 7093

5 rue Thomas Mann

F-75205 Paris Cedex 13

\section{Dr. Liesbeth De Mol}

Centre for Logic \& Philosophy of Science

Ghent University

Blandijnberg 2

B-9000 Gent

Prof. Dr. Marie-Jose DurandRichard

33 rue de Lilas

F-75019 Paris
Prof. Dr. Joachim Fischer

Ernst von Siemens Kunststiftung

Wittelsbacherplatz 2

80333 München

Prof. Dr. Matthieu Husson

7 rue Souchal

F-92110 Clichy

Prof. Dr. Agathe Keller

Universite Paris 7 - CNRS

Laboratoire SPHERE UMR 7219

Equipe Rehseis, Case 7093

5 rue Thomas Mann

F-75205 Paris Cedex 13

\section{Dr. Koolakkodlu Mahesh}

Universite Paris 7 - CNRS

Laboratoire SPHERE UMR 7219

Equipe Rehseis, Case 7093

5 rue Thomas Mann

F-75205 Paris Cedex 13

Prof. Dr. Clemency Montelle

Department of Mathematics

University of Canterbury

Private Bag 4800

Christchurch 8140

NEW ZEALAND

\section{Dr. Mathieu Ossendrijver}

Institute for the Study of the Ancient

World (ISAW)

New York University

15 East 84th St.

New York, NY 10028

USA

Prof. Dr. Christine Proust

18 rue de Turbigo

F-75002 Paris 


\section{Micah Ross}

International House

Kyoto Sangyo University

Motoyama, Kamigamo, Kita-ku

Kyoto 603-8555

JAPAN

Prof. Dr. Thomas Sonar

Institut Computational Mathematics

Technische Universität Braunschweig

Pockelstraße 14

38106 Braunschweig
Prof. Dr. Renate Tobies

Laboratorium Aufklärung

Friedrich-Schiller-Universität

Jentower. 8. Etage

Leutragraben 1

07743 Jena

Prof. Dr. Dominique Tournes

14 Chemin des Cypres

Bois de Nefles

F-97490 Sainte-Clotilde Reunion 
